\title{
Design and Characterization of the First Selective and Potent Mechanism-Based Inhibitor of Cytochrome P450 4Z1
}

John P. Kowalski ${ }^{\dagger}$, Matthew G. McDonald ${ }^{\dagger}$, Robert D. Pelletier ${ }^{\dagger}$, Helmut Hanenberg ${ }^{\ddagger}$, Constanze Wiek $^{\S}$, Allan E. Rettie ${ }^{\dagger, *}$

tDepartment of Medicinal Chemistry, School of Pharmacy, University of Washington, Seattle, WA 98105, USA

‡Department of Pediatrics III, University Children’s Hospital Essen, University of Duisburg-Essen, 45122 Essen, Germany

§Department of Otorhinolaryngology and Head/Neck Surgery, Heinrich-Heine University, 40225 Düsseldorf, Germany

${ }^{*}$ Corresponding author, email: rettie@uw.edu

\section{SUPPORTING INFORMATION}

\section{Table of Contents}

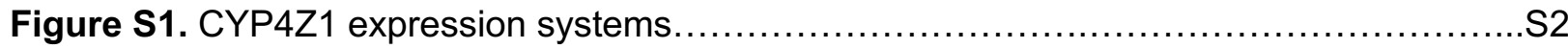

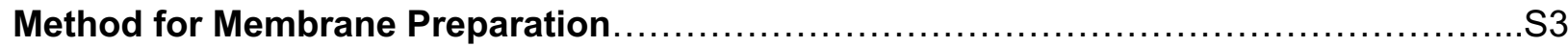

Figure S2. $I C_{50}$ and shifted-IC $C_{50}$ determination for inhibition of CYP4Z1 by $1-9 \ldots \ldots \ldots \ldots \ldots . . . .$.

Figure S3. $\mathrm{IC}_{50}$ and shifted-IC $\mathrm{C}_{50}$ determination for inhibition of CYP4 isozymes by $6 \ldots \ldots \ldots \ldots \ldots$......... 5

Figure S4. $I C_{50}$ and shifted-IC $C_{50}$ determination for inhibition of CYP4 isozymes by $7 \ldots \ldots \ldots \ldots . . . .6$

Figure S5. $\mathrm{IC}_{50}$ and shifted-IC $\mathrm{C}_{50}$ determination for inhibition of hepatic CYP isozymes by $6 \ldots . . . S 7$

Figure S6. $\mathrm{IC}_{50}$ and shifted-IC $\mathrm{C}_{50}$ determination for inhibition of hepatic CYP isozymes by $7 \ldots . . . \mathrm{S} 8$

Figure S7 Luc-4F2/3 metabolism kinetics for CYP4F2, CYP4F3a, and CYP4F3b.............S9

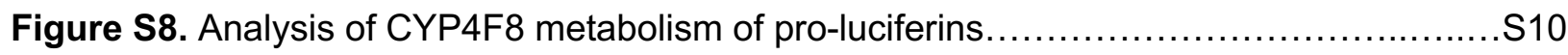

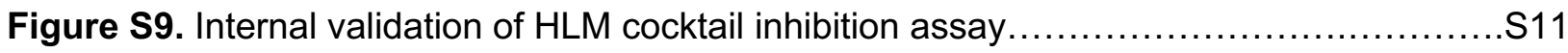

Figure S10. Inhibition of CYP4Z1-mediated AA Metabolism by 7 in HepG2 Membranes......S12

Figure S11. Inhibition of CYP4Z1 in HepG2 Cells and HepG2, T47D Cell Viability............S13

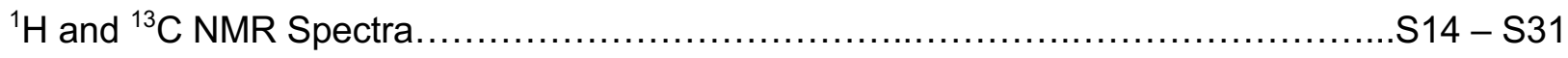




\section{A}

puc2CL6IPwo

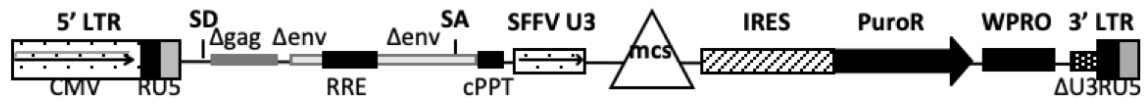

puc2CL6CYP4Z1colPwo

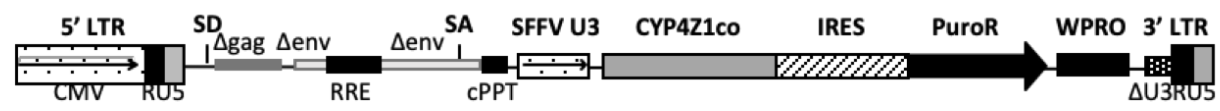

B

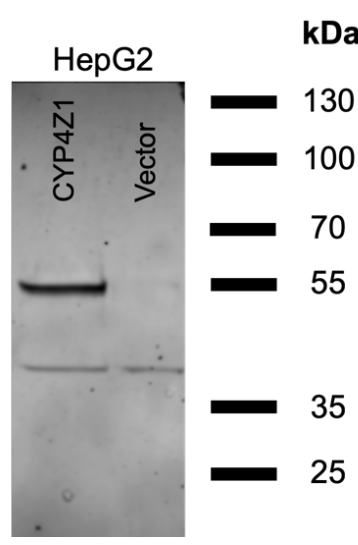

C

D
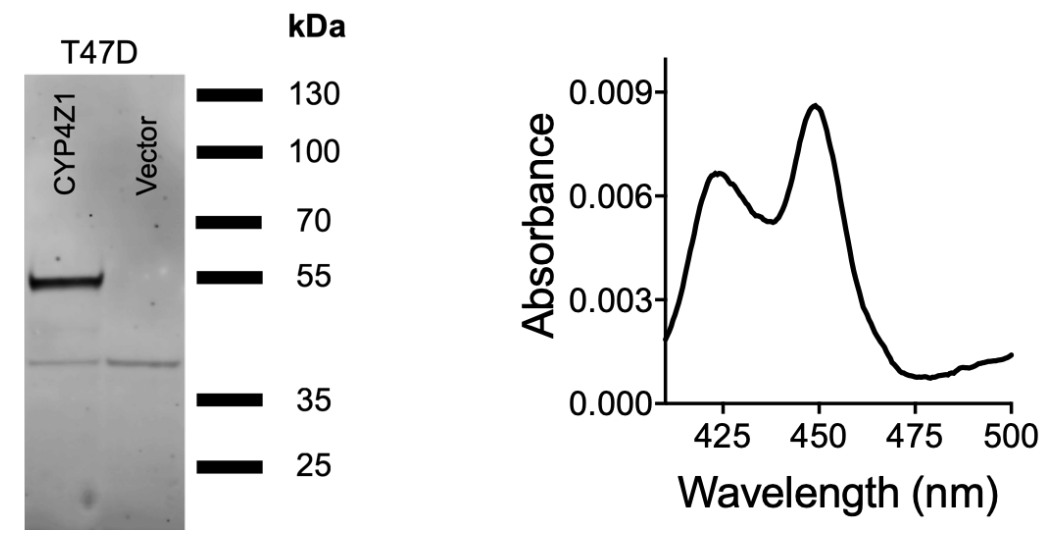

Figure S1. CYP4Z1 expression systems. Schematic outline of the lentiviral vector puc2CL6IPwo used for expression of codon-optimized (co) CYP4Z1 in both HepG2 cells (used for membrane preparations), and T47D cells (used for whole cell assays). CMV: CMV promoter; SD: splice donor; LTR: long terminal repeat; SA: splice acceptor; RRE: Rev responsive element; CPPT, central polypurine binding tract; SFFV U3: U3 promoter of the spleen focus-forming virus; mcs: multicloning site; IRES: internal ribosomal entry site; PuroR: puromycin resistance cDNA; WPRO, woodchuck hepatitis virus post-transcriptional regulatory element (optimized) (A). Western blot characterization of HepG2 (B) and T47D (C) cells modified with the above described lentivirus to express CYP4Z1 ( $\sim 55 \mathrm{kDa}$, source: Atlas Antibodies). No expression was detected in the vector control cell lines; the loading control GAPDH is also shown ( $\sim 37 \mathrm{kDa}$, source: Invitrogen). Carbon monoxide (CO) binding spectra, indicates $\sim 1 \mu \mathrm{M}$ CYP4Z1 in the HepG2 membranes via analysis of the absorbance at $450 \mathrm{~nm}$, the large absorbance signal at $420 \mathrm{~nm}$ is common to expression systems that contain other hemeproteins ${ }^{14}(\mathrm{D})$. 
Method for Membrane Preparation. CYP4Z1-HepG2, CYP4F8-HepG2, and VectorHepG2 membranes were prepared as follows: HepG2 cells were modified by lentiviral transduction to express CYP4Z1, CYP4F8, or with a control vector, as previously described. ${ }^{49,50}$ A schematic outline of the lentiviral vector system has been provided in the Supporting Information (Figure S1A). Western blot analysis was performed as previously described. ${ }^{8}$ The stably transduced HepG2 cells were grown in tissue culture media consisting of DMEM, $10 \%$ FBS, $1 \%$ pen/strep, and $10 \mathrm{mM} \mathrm{HEPES}$, and were selected with puromycin treatment $(2 \mu \mathrm{g} / \mathrm{mL})$ over a 7-day period as previously described. ${ }^{51}$ HepG2 cell lines were scaled up by expanding over a duration of 2.5-3 weeks (split 1:10 twice), with periodic refeeding at $2 \mu \mathrm{g} / \mathrm{mL}$ puromycin to maintain selection, ultimately generating $100 \times 15 \mathrm{~cm} 90+\%$ confluent plates. Approximately $1 \times 10^{9}$ cells were harvested, washed thrice with PBS, homogenized on ice by sonication and membranes prepared at $100,000 \times g$ for 60 min after first subjecting the homogenate to a very low speed spin of $1,000 \times g$ for 5 min to remove large cellular debris. The pellets were

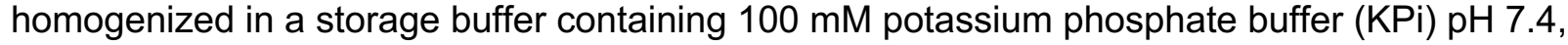
$20 \%$ glycerol, and $1 \mathrm{mM}$ EDTA. CYP450 concentration was measured from the conventional carbon monoxide difference spectrum. ${ }^{14}$ These procedures yielded a specific content of 81 pmol CYP4Z1/mg protein ( 15 nanomoles total) in the CYP4Z1-HepG2 membranes for our metabolic studies; no CYP4Z1 was detectable in the Vector-HepG2 membranes. The CYP4F8-HepG2 membranes had a specific content of $20 \mathrm{pmol}$ CYP4F8/mg protein ( $\sim 3$ nanomoles total). 

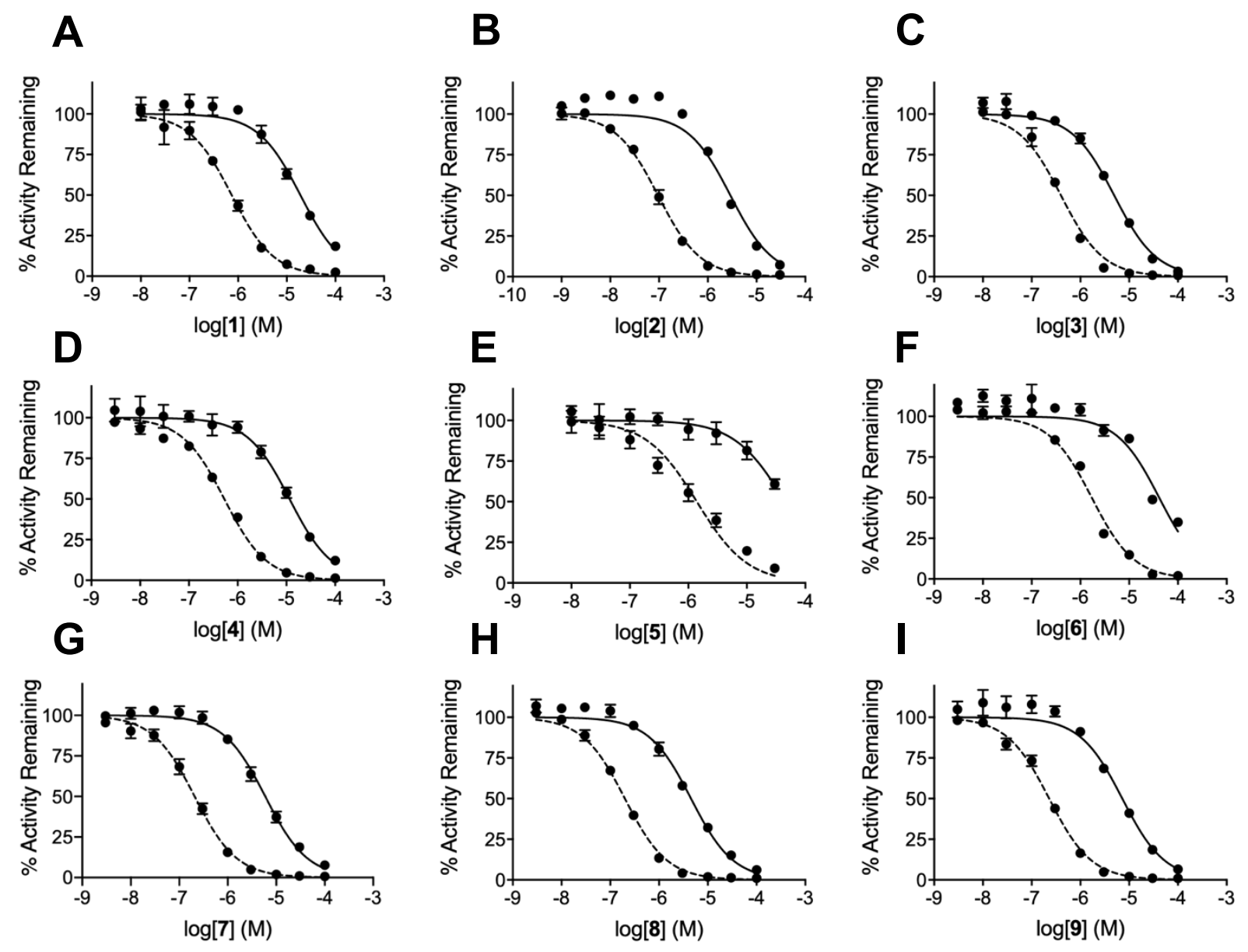

Figure S2. $I C_{50}$ and shifted-IC $C_{50}$ determination for inhibition of CYP4Z1 by $1-9$. CYP4Z1 inhibition from treatment with compounds $1(A), 2(B), 3(C), 4(D), 5(E), 6(F), 7(G), 8$ (H), and 9 (I) was determined from the dose-response curves of percent remaining activity of CYP4Z1-mediated Luc-BE O-debenzylation, compared to treatment with vehicle (DMSO). The minus NADPH pre-incubation reactions (solid lines) correspond to the reported $\mathrm{IC}_{50}$ values and the plus NADPH pre-incubation reactions (dashed lines) correspond to the reported shifted-IC $\mathrm{C}_{50}$ values. Data shown represents the mean and standard deviation from multiple independent experiments. 

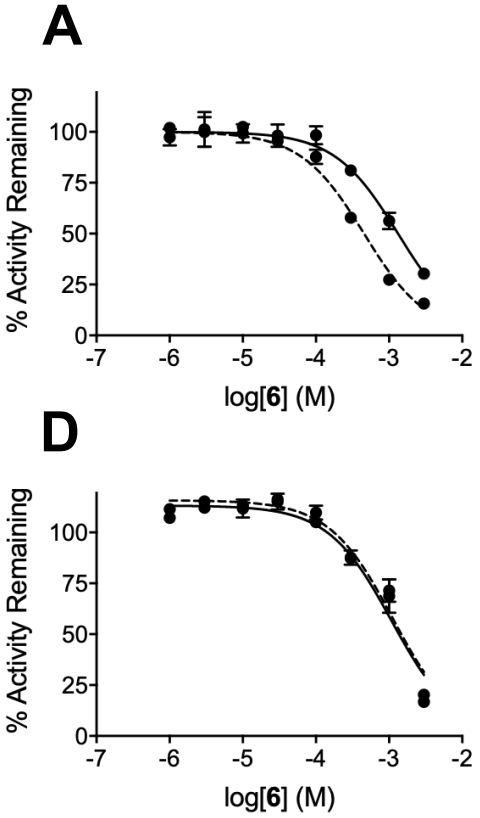

B

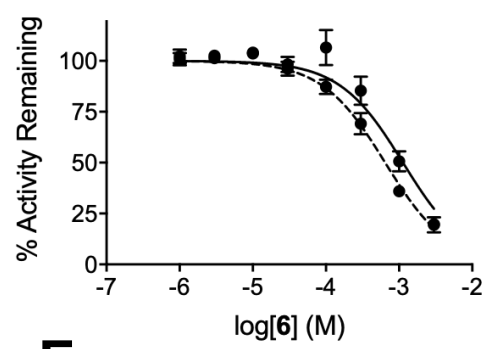

E

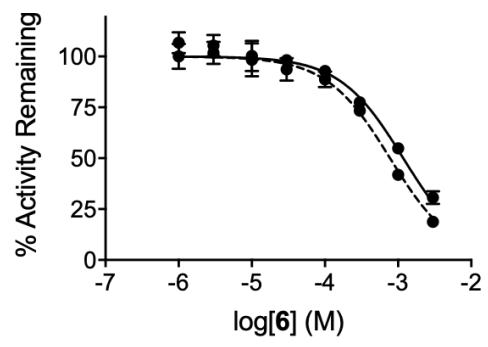

C

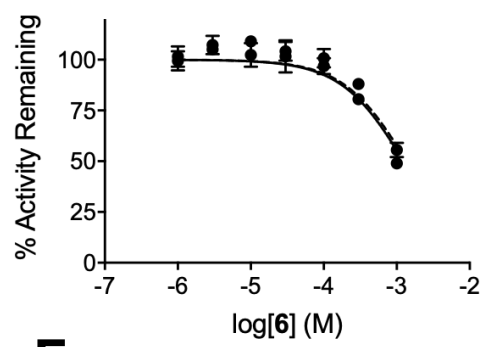

$\mathbf{F}$

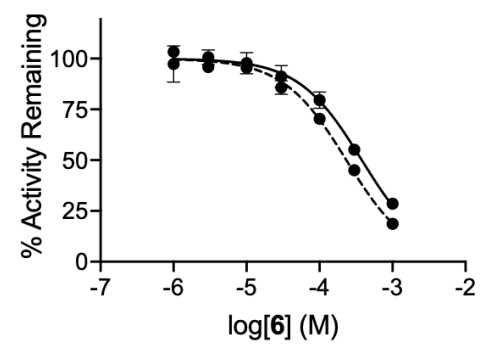

Figure S3. $\mathrm{IC}_{50}$ and shifted-IC $\mathrm{C}_{50}$ determination for inhibition of CYP4 isozymes by 6. Inhibition of CYP4A11 Luc-4A O-demethylation (A), CYP4F2 (B), CYP4F3a (C), and CYP4F3b Luc4F2/3 O-(4-methylthio)-debenzylation (D), CYP4F8 (E), and CYP4F12 Luc-BE O-

debenzylation $(\mathbf{F})$ was determined from the dose-response curves of percent remaining activity from treatment with inhibitor 6 compared to treatment with vehicle (DMSO). The minus NADPH pre-incubation reactions (solid lines) correspond to the reported $\mathrm{IC}_{50}$ values and the plus NADPH pre-incubation reactions (dashed lines) correspond to the reported shifted-I $\mathrm{C}_{50}$ values. Data shown represents the mean and standard deviation from multiple independent experiments. Of note, $\mathrm{IC}_{50}$ determinations for inhibition of CYP4F3a by 6 are an approximation as concentrations $>1 \mathrm{mM}$ to fully define $50 \%$ inhibition were not tested due to lack of enzyme. 

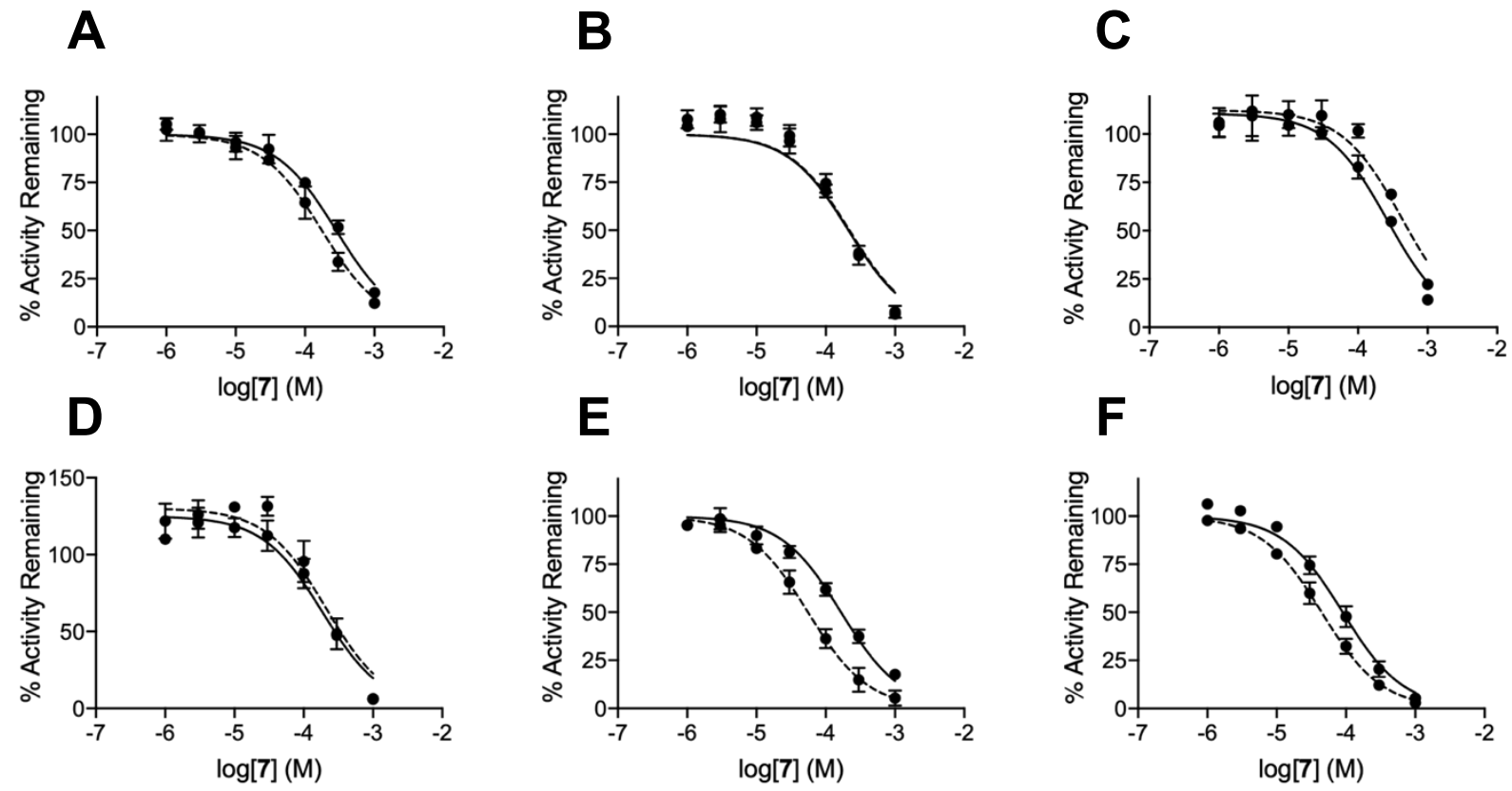

Figure S4. $\mathrm{IC}_{50}$ and shifted-IC $\mathrm{C}_{50}$ determination for inhibition of CYP4 isozymes by 7. Inhibition of CYP4A11 Luc-4A O-demethylation (A), CYP4F2 (B), CYP4F3a (C), and CYP4F3b Luc4F2/3 O-(4-methylthio)-debenzylation (D), CYP4F8 (E), and CYP4F12 Luc-BE Odebenzylation $(\mathbf{F})$ was determined from the dose-response curves of percent remaining activity from treatment with inhibitor 7 compared to treatment with vehicle (DMSO). The minus NADPH pre-incubation reactions (solid lines) correspond to the reported $I C_{50}$ values and the plus NADPH pre-incubation reactions (dashed lines) correspond to the reported shifted-IC $\mathrm{C}_{50}$ values. Data shown represents the mean and standard deviation from multiple independent experiments. Of note, CYP4F3b exhibited what may be modelled as a bellshaped dose-response curve (D), where low concentrations of 7 stimulated CYP4F3b Luc$4 \mathrm{~F} 2 / 3$ metabolism and higher concentrations inhibited the enzyme, however, this was not used for $\mathrm{IC}_{50}$ determinations, nor investigated further. 


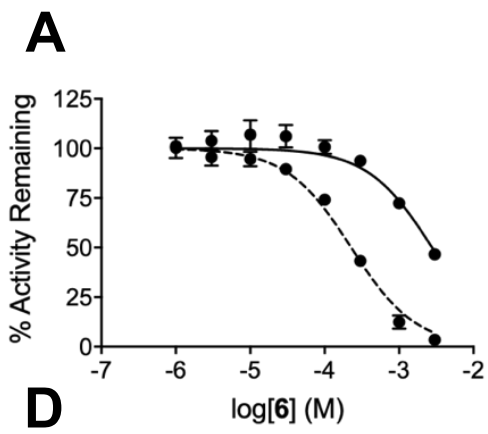

\section{B}
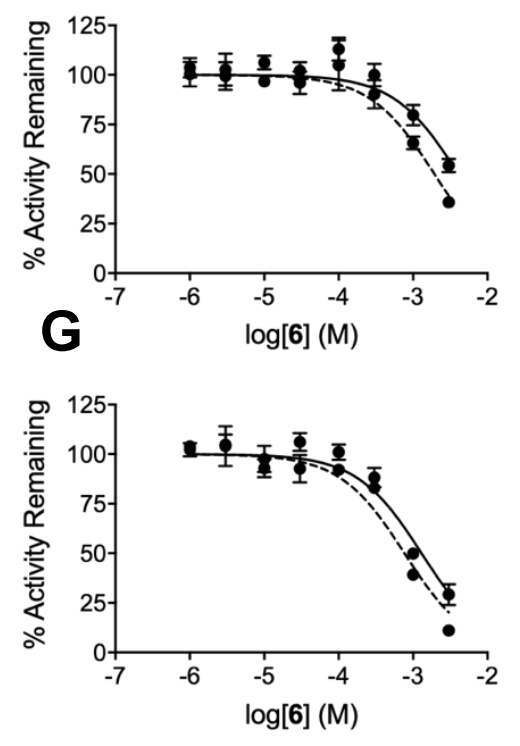
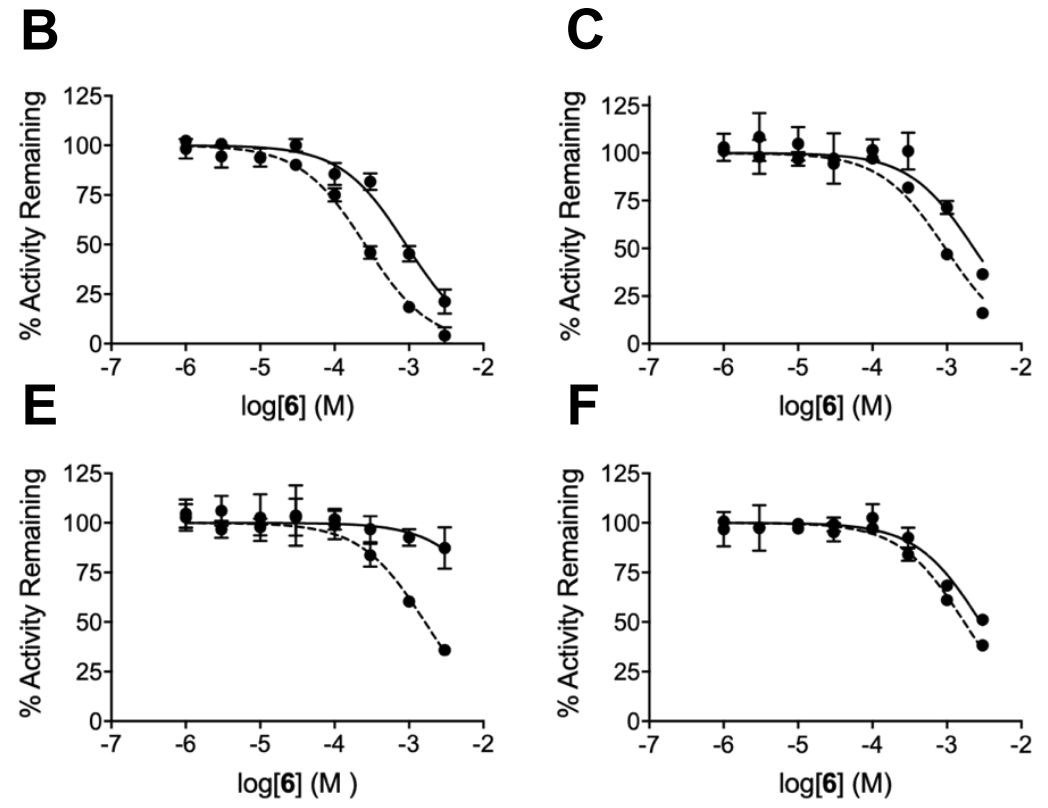

Figure S5. $\mathrm{IC}_{50}$ and shifted-IC $\mathrm{C}_{50}$ determination for inhibition of hepatic CYP isozymes by 6 . Inhibition of CYP1A2 phenacetin O-deethylation (A), CYP2B6 bupropion hydroxylation (B), CYP2C8 amodiaquine $N$-deethylation (C), CYP2C9 tolbutamide methyl-hydroxylation (D), CYP2C19 (S)-mephenytoin 4'-hydroxylation (E), CYP2D6 dextromethorphan Odemethylation (F), and CYP3A4/5 midazolam 1'-hydroxylation (G) was determined from the dose-response curves of percent remaining activity from treatment with inhibitor $\mathbf{6}$ compared to treatment with vehicle (DMSO). The minus NADPH pre-incubation reactions (solid lines) correspond to the reported $\mathrm{IC}_{50}$ values and the plus NADPH pre-incubation reactions (dashed lines) correspond to the reported shifted- $\mathrm{IC}_{50}$ values. Data shown represents the mean and standard deviation from multiple independent experiments. 

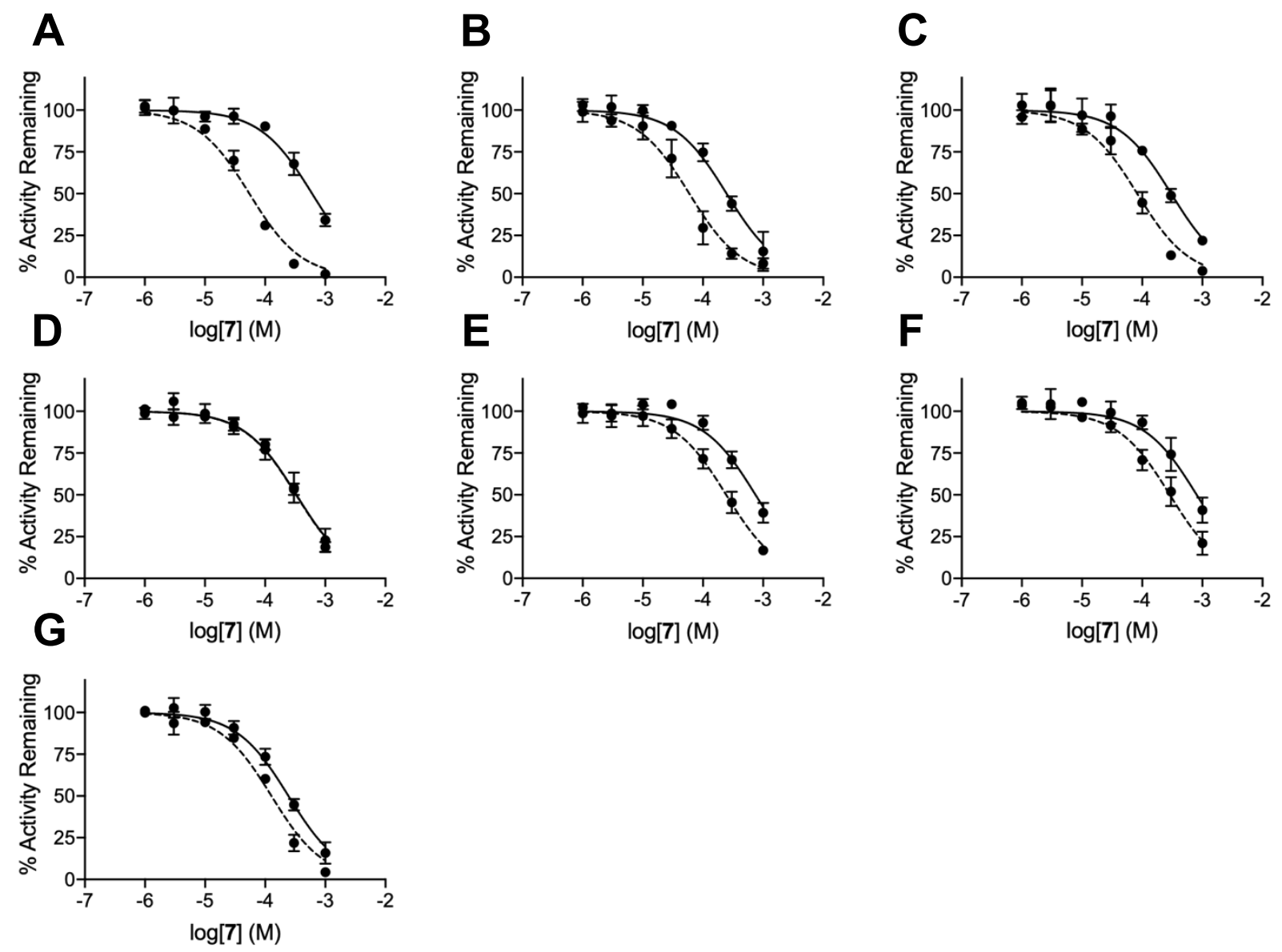

Figure S6. IC $\mathrm{C}_{50}$ and shifted-IC $\mathrm{C}_{50}$ determination for inhibition of hepatic CYP isozymes by 7. Inhibition of CYP1A2 phenacetin O-deethylation (A), CYP2B6 bupropion hydroxylation (B), CYP2C8 amodiaquine $\mathrm{N}$-deethylation (C), CYP2C9 tolbutamide methyl-hydroxylation (D), CYP2C19 (S)-mephenytoin 4'-hydroxylation (E), CYP2D6 dextromethorphan Odemethylation $(\mathbf{F})$, and CYP3A4/5 midazolam 1'-hydroxylation $(\mathbf{G})$ was determined from the dose-response curves of percent remaining activity from treatment with inhibitor $\mathbf{7}$ compared to treatment with vehicle (DMSO). The minus NADPH pre-incubation reactions (solid lines) correspond to the reported $\mathrm{IC}_{50}$ values and the plus NADPH pre-incubation reactions (dashed lines) correspond to the reported shifted- $\mathrm{IC}_{50}$ values. Data shown represents the mean and standard deviation from multiple independent experiments. 

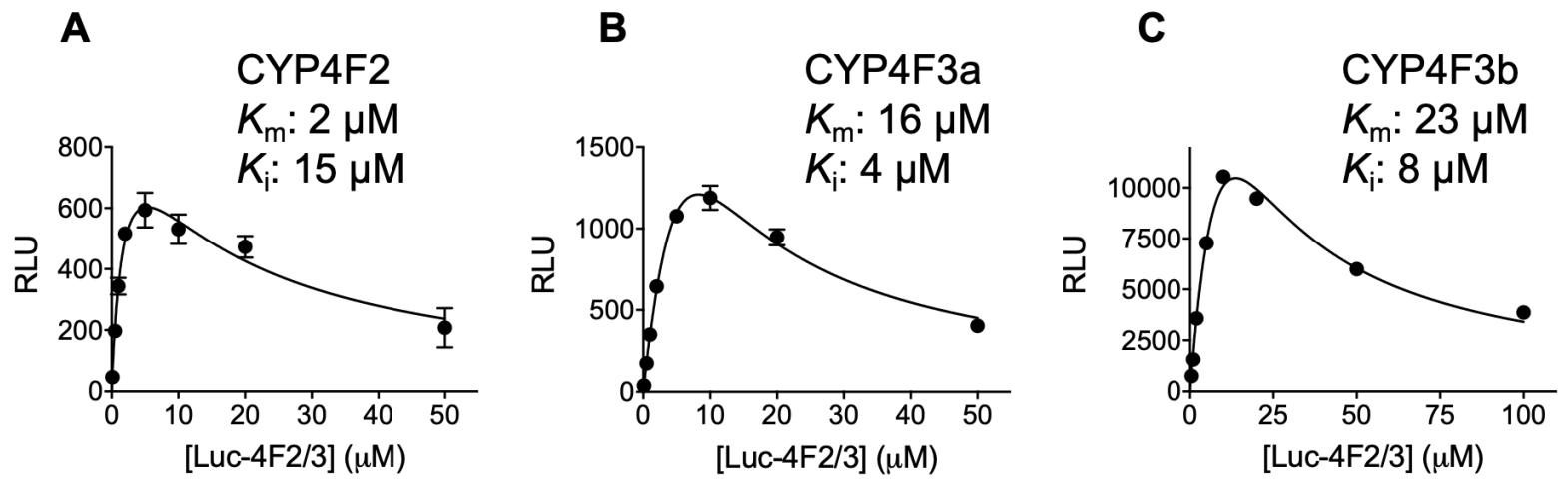

Figure S7. Luc-4F2/3 metabolism kinetics for CYP4F2, CYP4F3a, and CYP4F3b. 4F2 (A), 4F3a (B), and 4F3b (C) all displayed substrate inhibition kinetics; therefore, the ABT-analog inhibition studies were performed at the probe substrate concentration of $2 \mu \mathrm{M}$ for all three enzymes. This probe substrate concentration utilized was approximately within the linear phases of turnover and $\leq K_{\mathrm{m}}$ and $<K_{\mathrm{i}}$ values. Data shown represents the mean and standard deviation from three replicates. 


Luc-4A

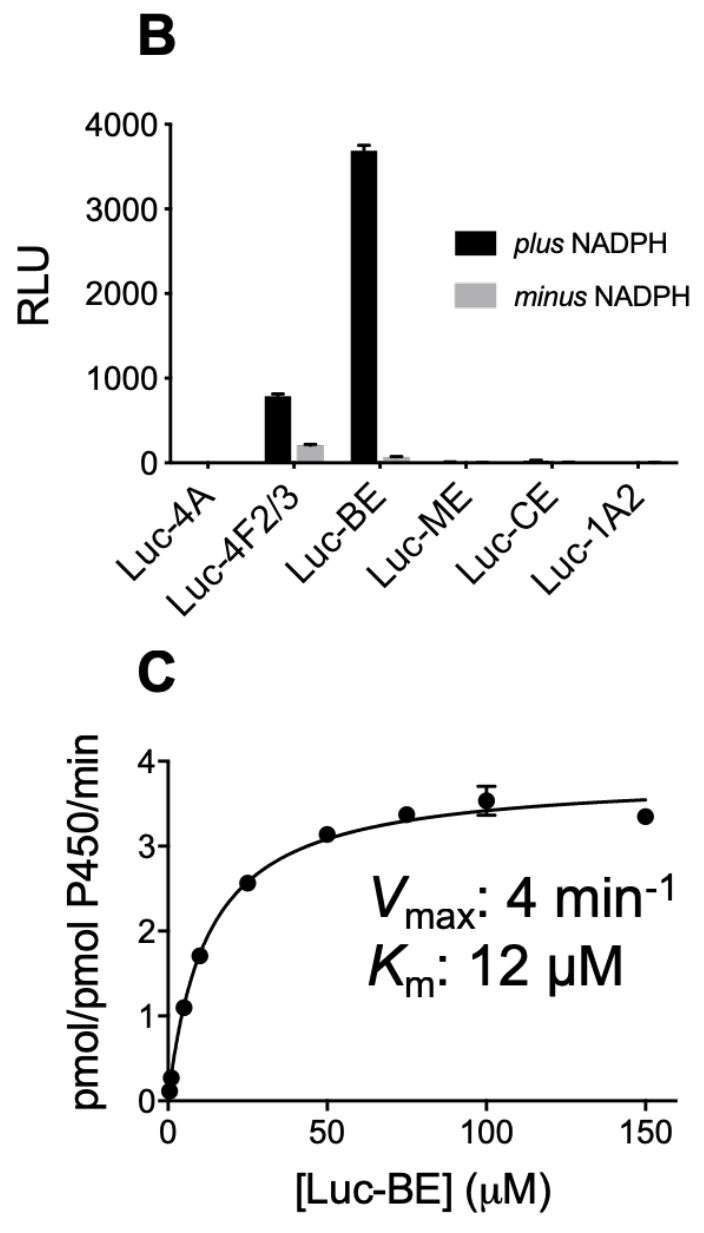

Figure S8. Analysis of CYP4F8 metabolism of pro-luciferins. Chemical structures of Promega's pro-luciferins used for screening (A). Screening of six different pro-luciferins for metabolism by CYP4F8 showed Luc-BE as a potential probe substrate (B). Kinetic analysis of CYP4F8mediated Luc-BE turnover shows a $V_{\max }=4 \mathrm{pmol} / \mathrm{pmol} \mathrm{CYP} 4 \mathrm{~F} 8 / \mathrm{min}$ and a $K_{\mathrm{m}}=12 \mu \mathrm{M}(\mathrm{C})$. Data shown represents the mean and standard deviation from three replicates. 


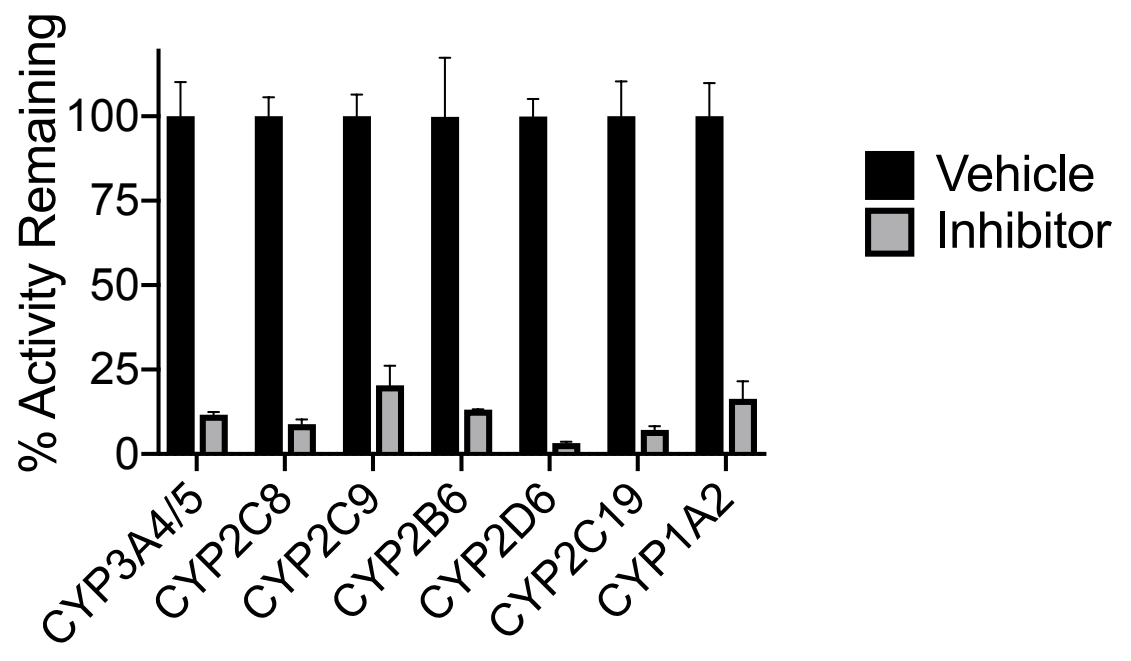

Figure S9. Internal validation of HLM cocktail inhibition assay. Inhibition of CYP-3A4/5, -2C8, -2C9, -2B6, -2D6, -2C19, -1A2 was assessed using ketoconazole $(0.5 \mu \mathrm{M})$, quercetin $(20$ $\mu \mathrm{M})$, sulfaphenazole $(2.5 \mu \mathrm{M})$, ticlopidine $(5 \mu \mathrm{M})$, quinidine $(2.5 \mu \mathrm{M})$, ticlopidine $(17.5 \mu \mathrm{M})$, and furafylline $(20 \mu \mathrm{M})$, respectively. The concentrations used were $\sim 5 \mathrm{X}$ literature reported $\mathrm{IC}_{50}$ values. The percent remaining activity after inhibition (as compared to vehicle control) is within error to full $\mathrm{IC}_{50}$ data when both cocktail and single substrate inhibition experiments are performed using HLM and these conditions. ${ }^{33}$ Data shown represents the mean and standard deviation from three replicates. 


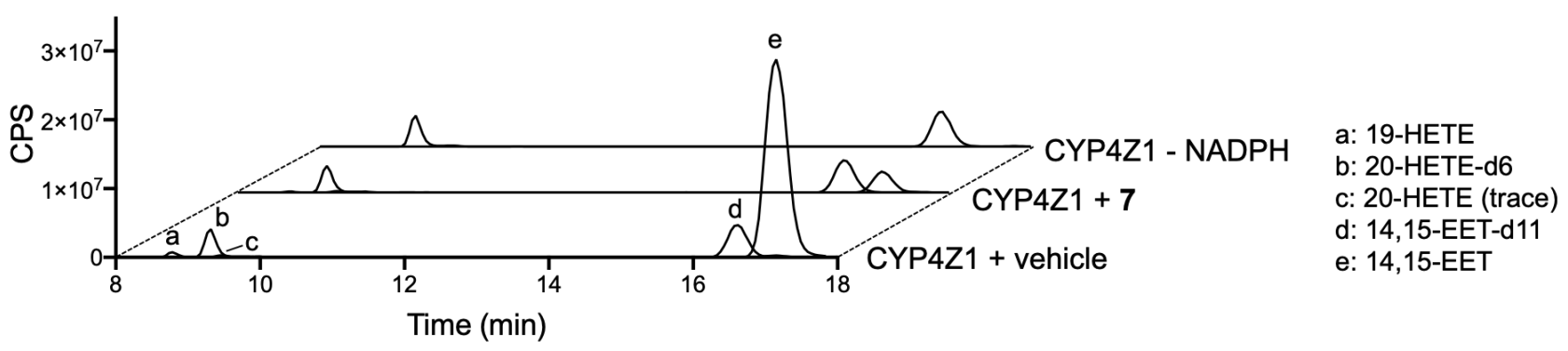

Figure S10. Inhibition of CYP4Z1-mediated AA Metabolism by 7 in HepG2 Membranes. After a 30-minute preincubation, treatment with $3 \mu \mathrm{M}$ of 7 results in $\sim 90 \%$ loss of CYP $4 Z 1$ activity, relative to vehicle, as assessed by comparing PARs for 14,15-EET production. The substrate AA was incubated with CYP4Z1 at $75 \mu \mathrm{M}$. No significant AA metabolism was observed when NADPH cofactor was not included in the incubation. Equal amounts of each internal standard (100 ng) were added prior to sample work-up. 
A

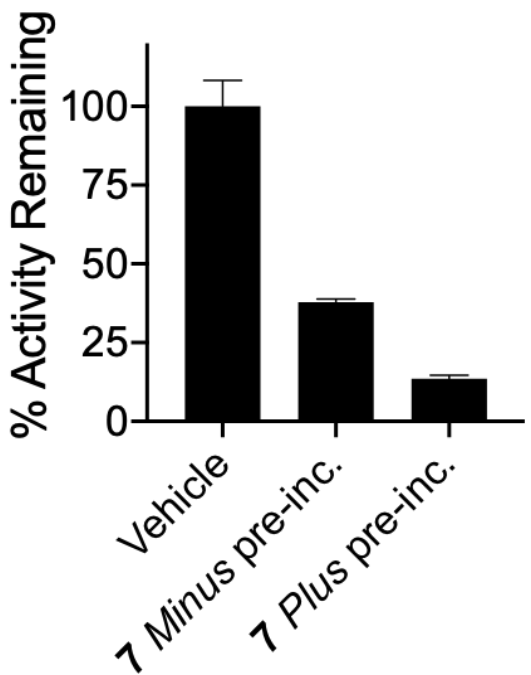

B

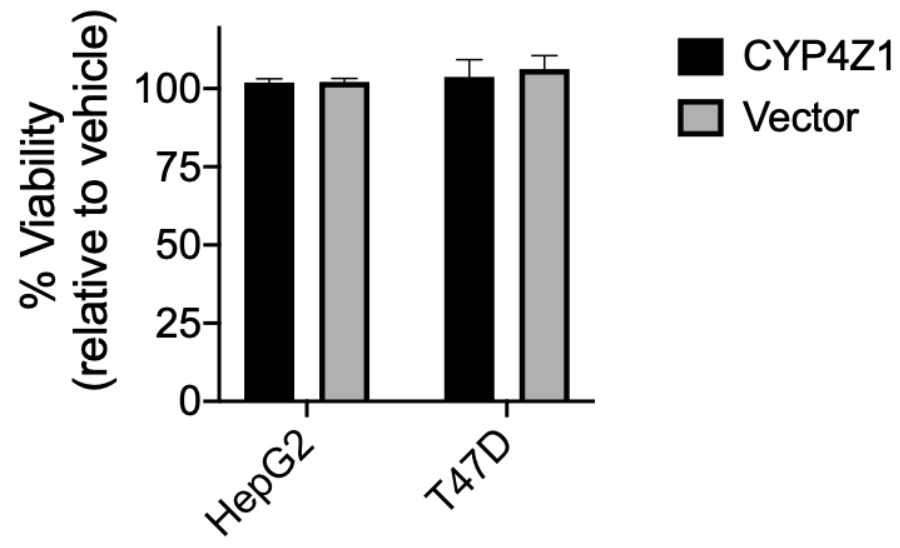

Figure S11. Inhibition of CYP4Z1 in HepG2 Cells and HepG2, T47D Cell Viability. CYP4Z1and vector-HepG2 cells were seeded into 96 -well white-walled plates at 15,000 cells/well in $100 \mu \mathrm{L}$ of cell culture media. A $1000 \times$ stock of inhibitor 7 , or DMSO vehicle, was diluted into a $100 \times$ stock solution in tissue culture medium and added to achieve a final concentration of 3 $\mu \mathrm{M}$ (Plus pre-inc.) and 24 hours later, a different subset of wells received inhibitor $\mathbf{7}$ at a final concentration of $3 \mu \mathrm{M}$ (Minus pre-inc.). Immediately following, Luc-BE was added to all wells to achieve a final concentration of $30 \mu \mathrm{M}$ and the cells were incubated for a further 1 hour, and then assayed as described in the Experimental Section. In whole HepG2 cells, CYP4Z1mediated Luc-BE O-debenzylation was inhibited $\sim 63 \%$ without a pre-incubation, and $\sim 86 \%$ with a pre-incubation, by inhibitor $\mathbf{7}$ at $3 \mu \mathrm{M}(\mathbf{A})$. Minimal Luc-BE O-debenzylation was observed in the vector-HepG2 cells (data not shown). Using the same seeding and stock solutions outlined above, both CYP4Z1 and vector-HepG2, -T47D cells received inhibitor 7 to achieve a final concentration of $3 \mu \mathrm{M}$. The cells were assessed 24 hours later using Promega's CellTiter-Glo Luminescent Cell Viability Assay and the percent viability, relative to vehicle treated cells, was compared. No cytotoxicity from treatment with 7 at $3 \mu \mathrm{M}$ was observed for any of the cell lines under the conditions tested (B). For both $\mathbf{A}$ and $\mathbf{B}$, shown is the average and SD from three replicates. 
${ }^{1} \mathrm{H}$ NMR $\left(500 \mathrm{MHz}, \mathrm{CDCl}_{3}\right)$

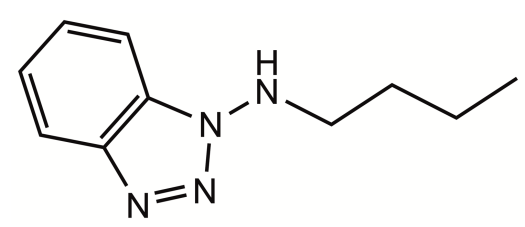

1

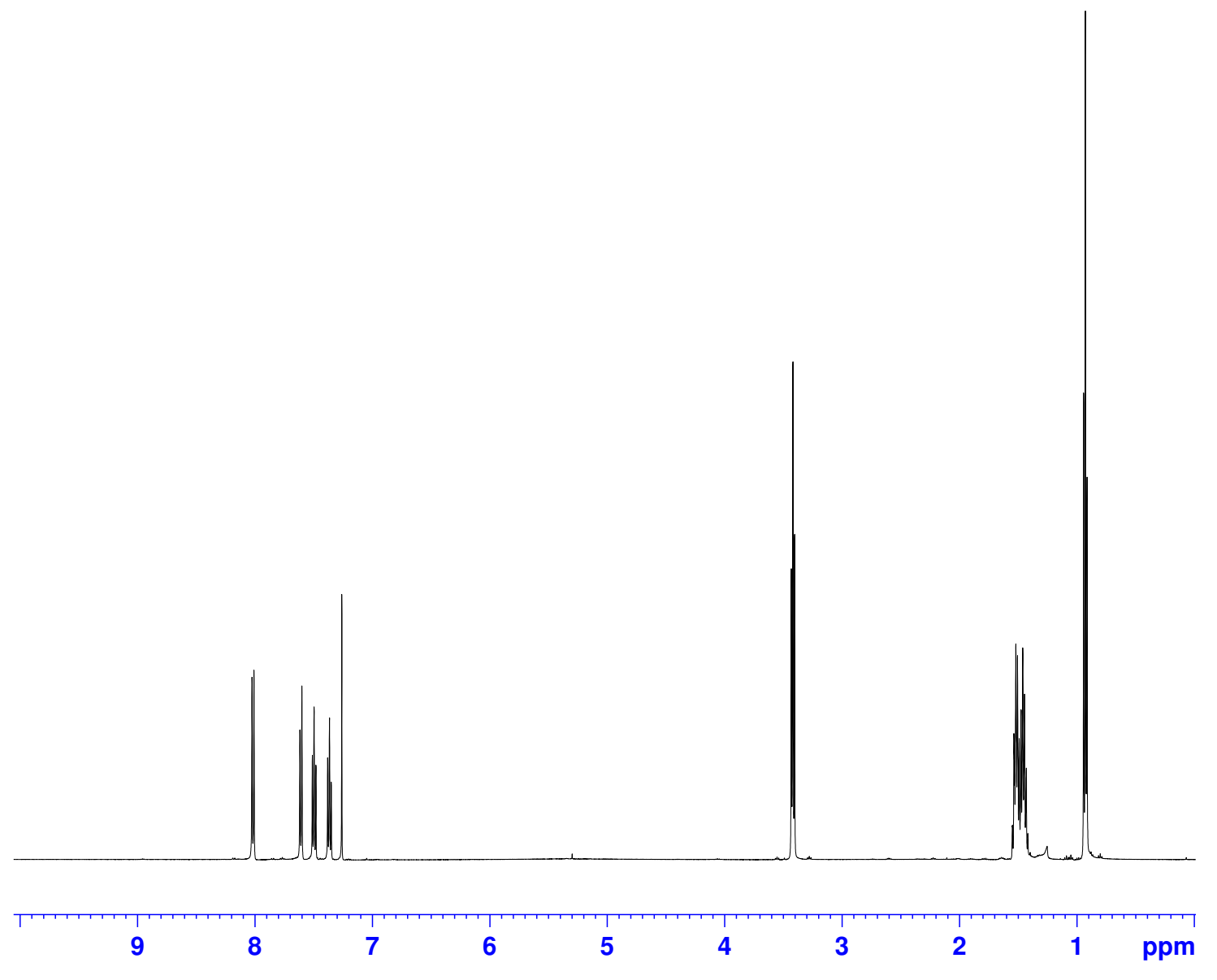


${ }^{13} \mathrm{C}$ NMR (125 MHz, $\left.\mathrm{CDCl}_{3}\right)$<smiles>CCCCNn1nnc2ccccc21</smiles>

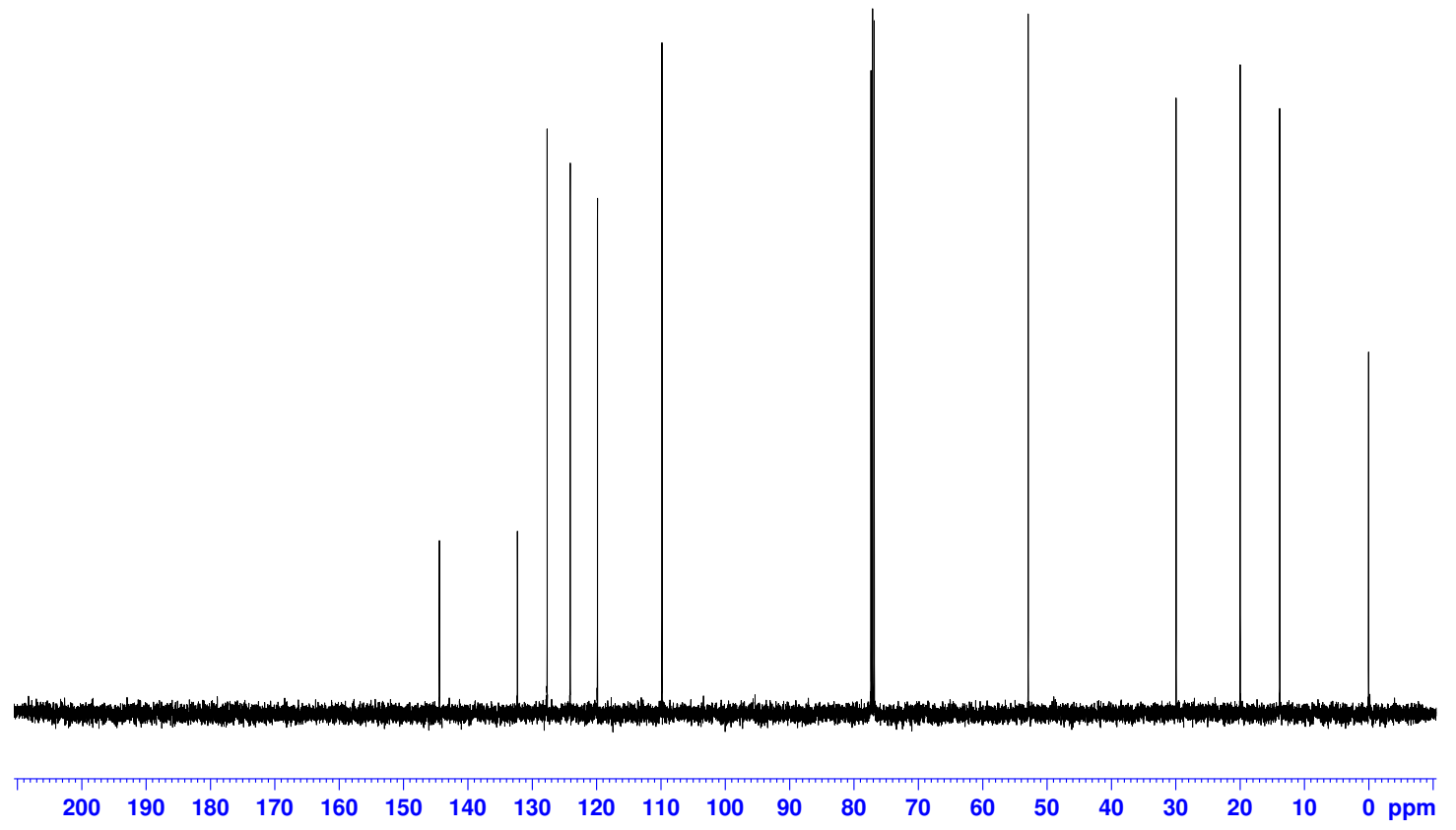


${ }^{1} \mathrm{H}$ NMR $\left(500 \mathrm{MHz}, \mathrm{CDCl}_{3}\right)$

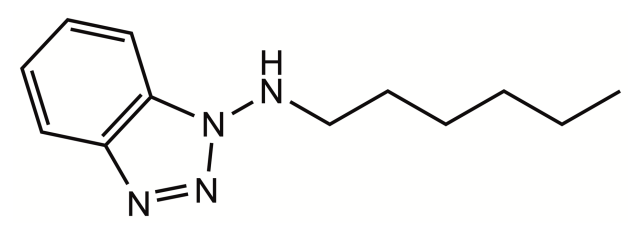

2

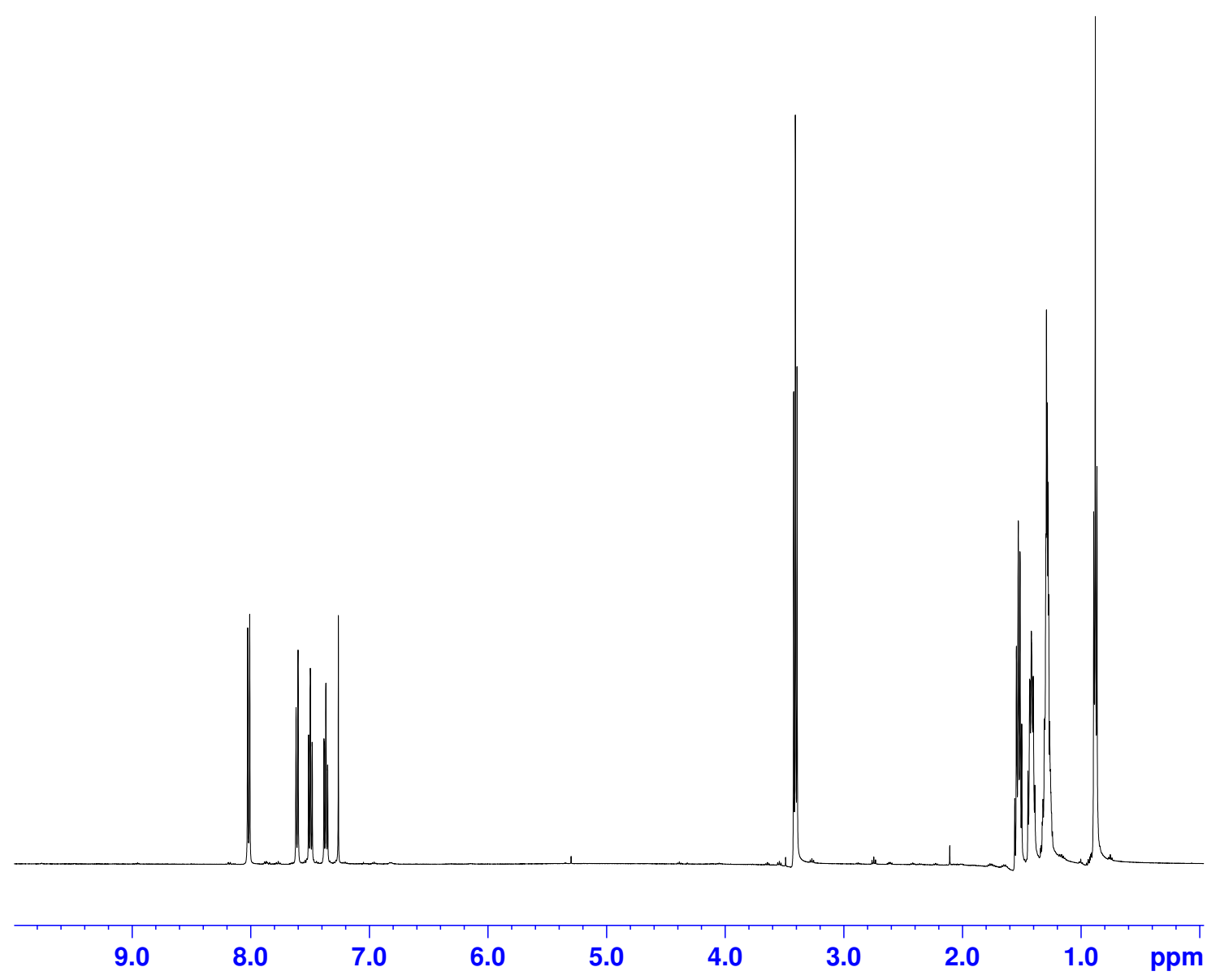


${ }^{13} \mathrm{C}$ NMR (125 MHz, $\left.\mathrm{CDCl}_{3}\right)$

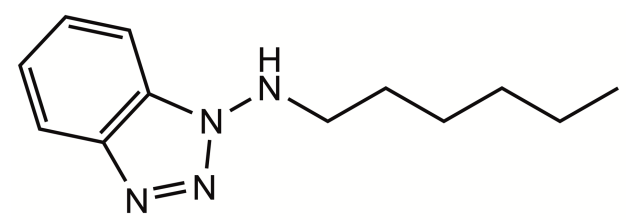

2

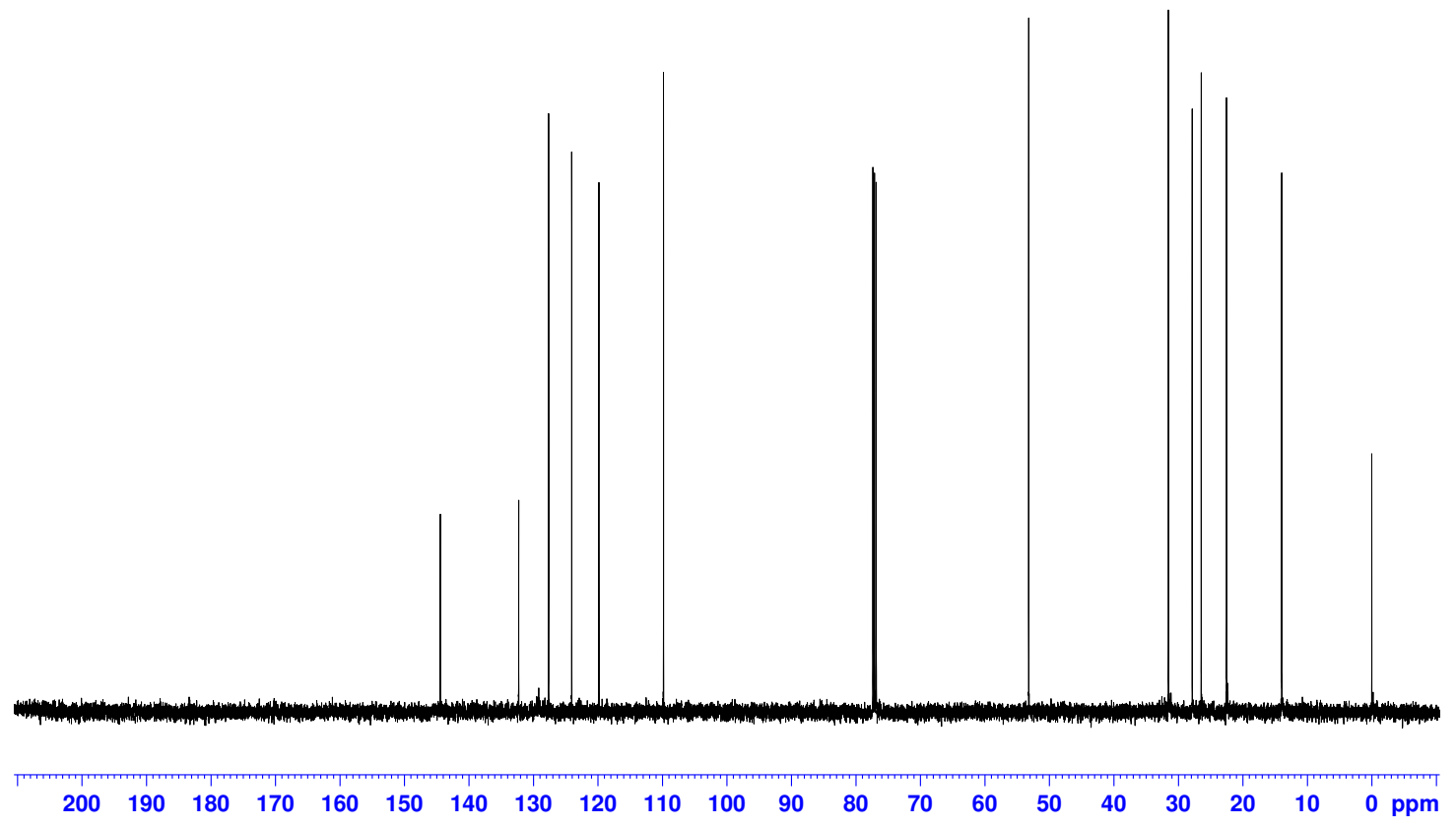


${ }^{1} \mathrm{H}$ NMR $\left(500 \mathrm{MHz}, \mathrm{CDCl}_{3}\right)$

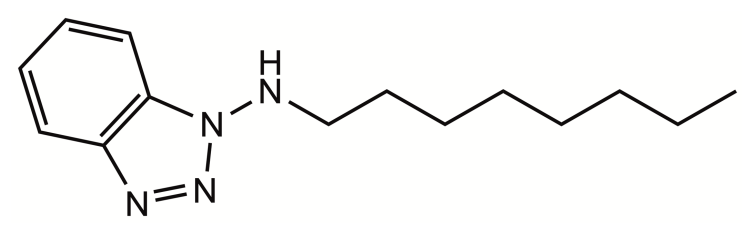

3

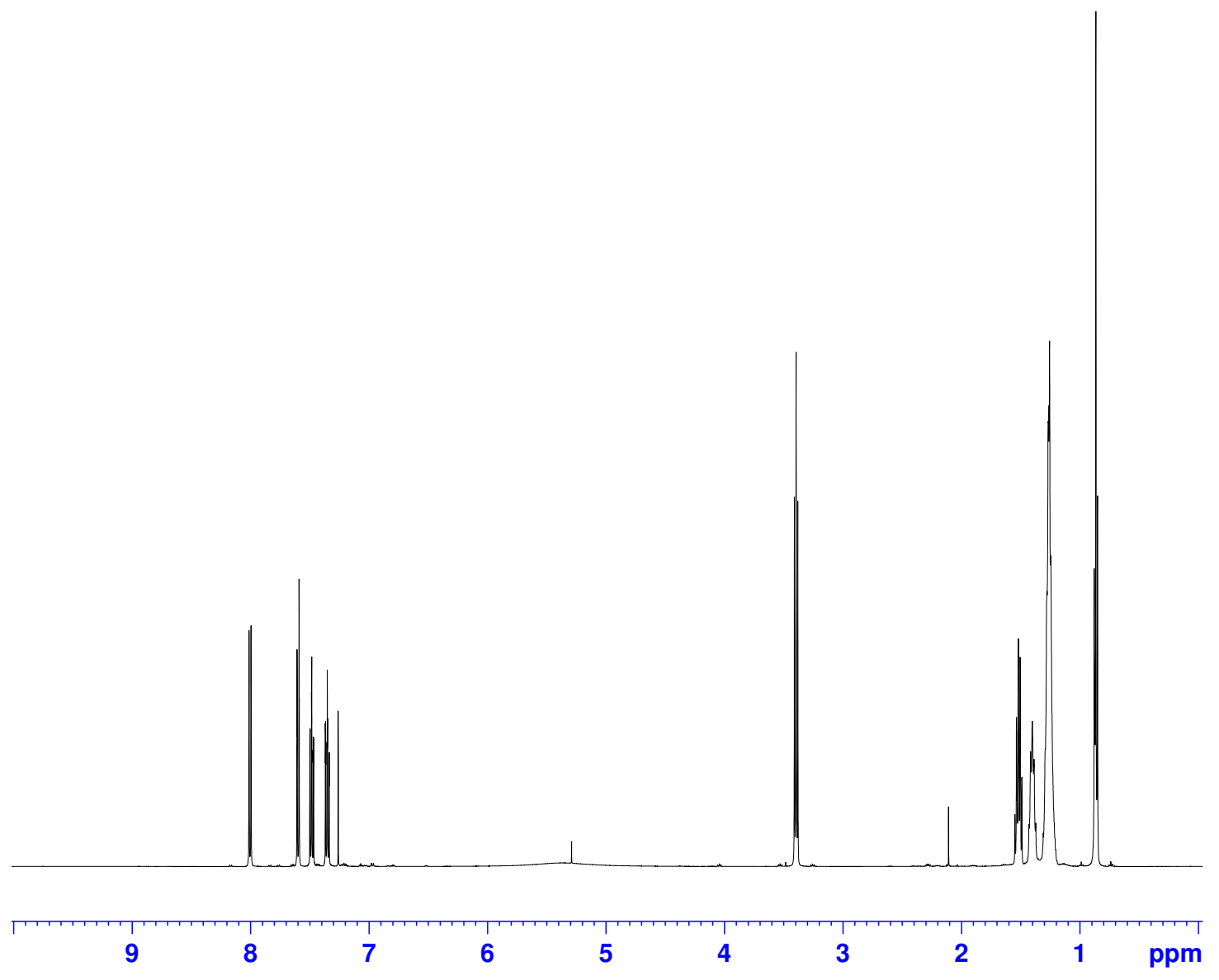


${ }^{13} \mathrm{C}$ NMR (125 MHz, $\left.\mathrm{CDCl}_{3}\right)$

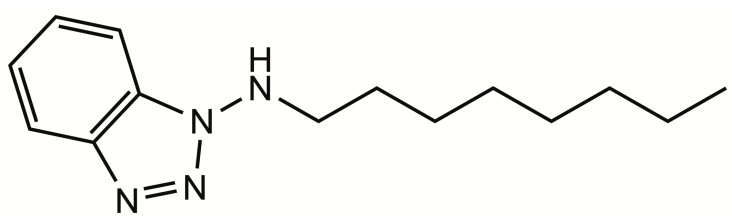

3

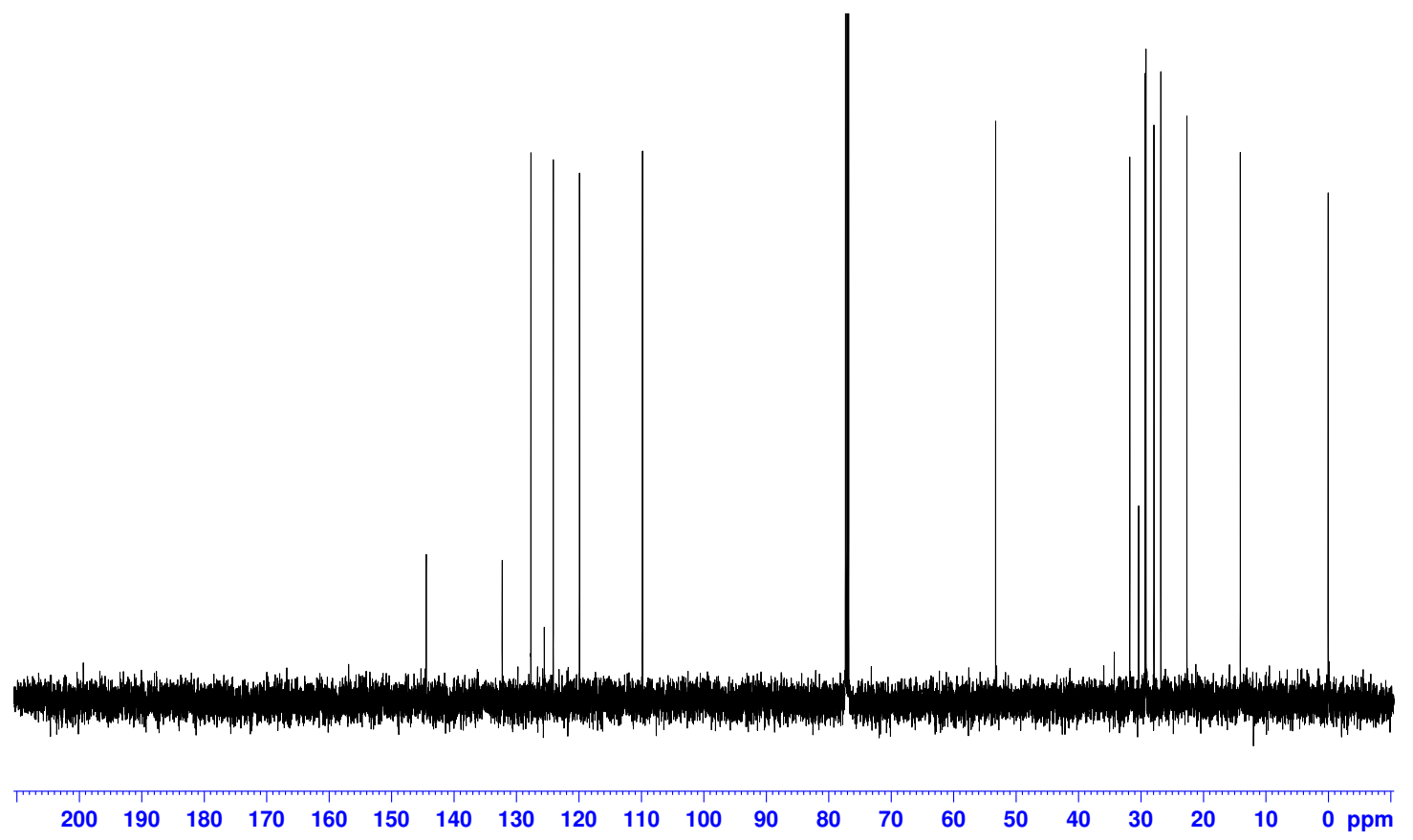


${ }^{1} \mathrm{H}$ NMR $\left(500 \mathrm{MHz}, \mathrm{CDCl}_{3}\right)$

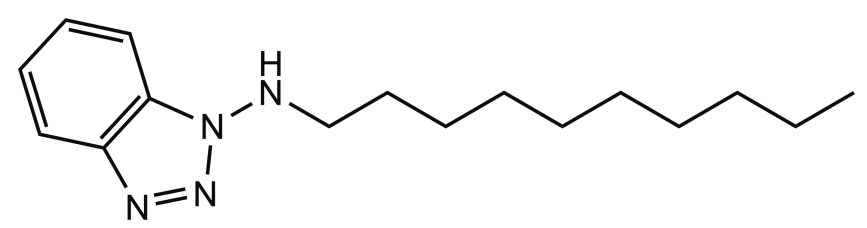

4

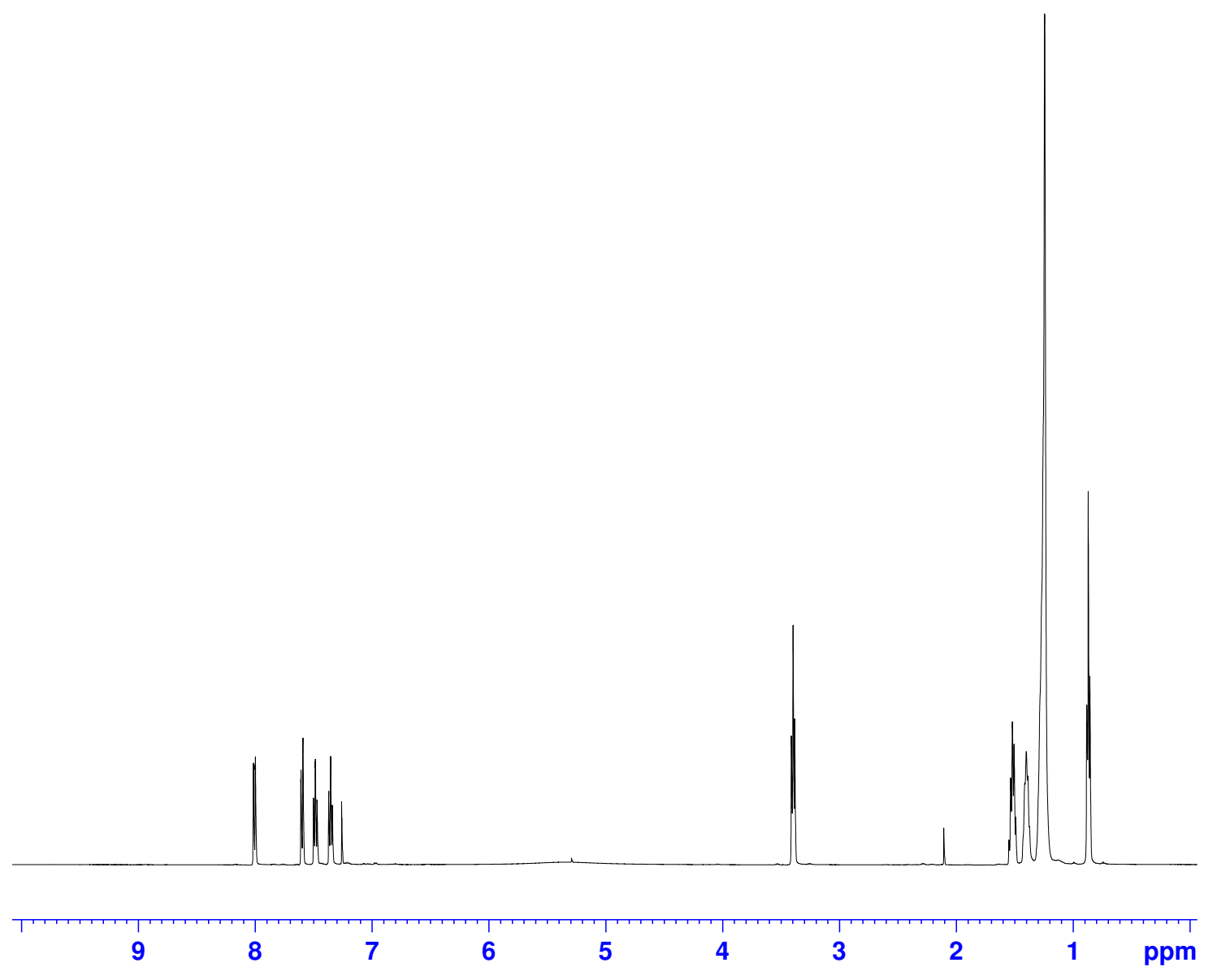


${ }^{13} \mathrm{C}$ NMR (125 MHz, $\left.\mathrm{CDCl}_{3}\right)$

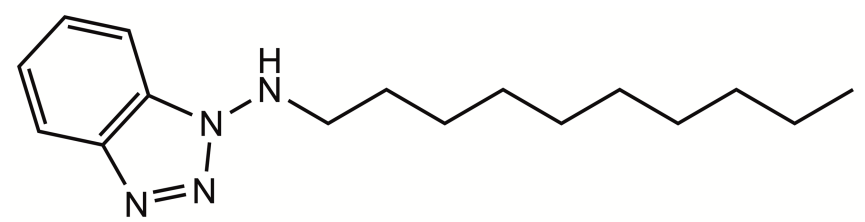

4

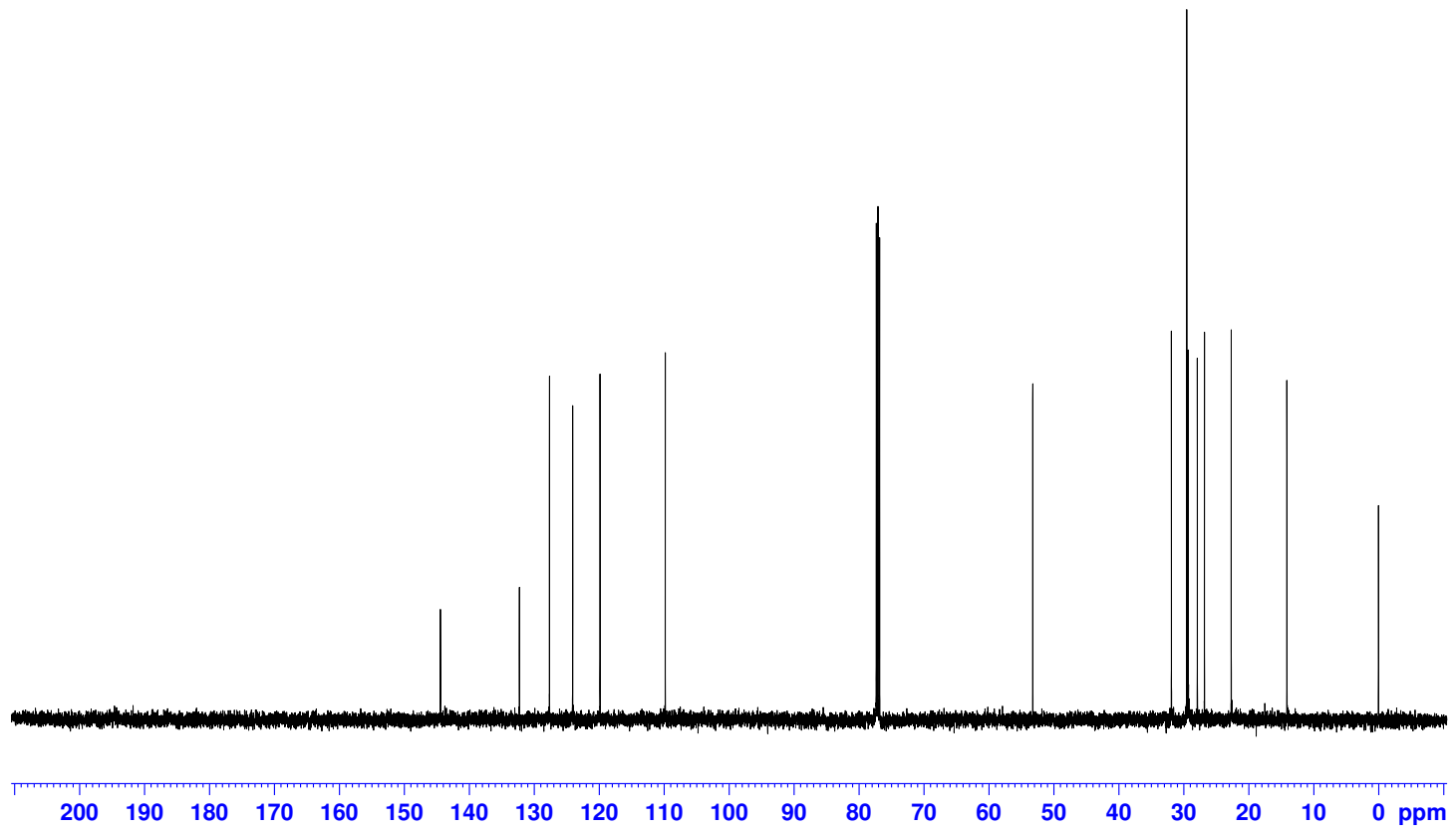


${ }^{1} \mathrm{H}$ NMR $\left(500 \mathrm{MHz}, \mathrm{CDCl}_{3}\right)$
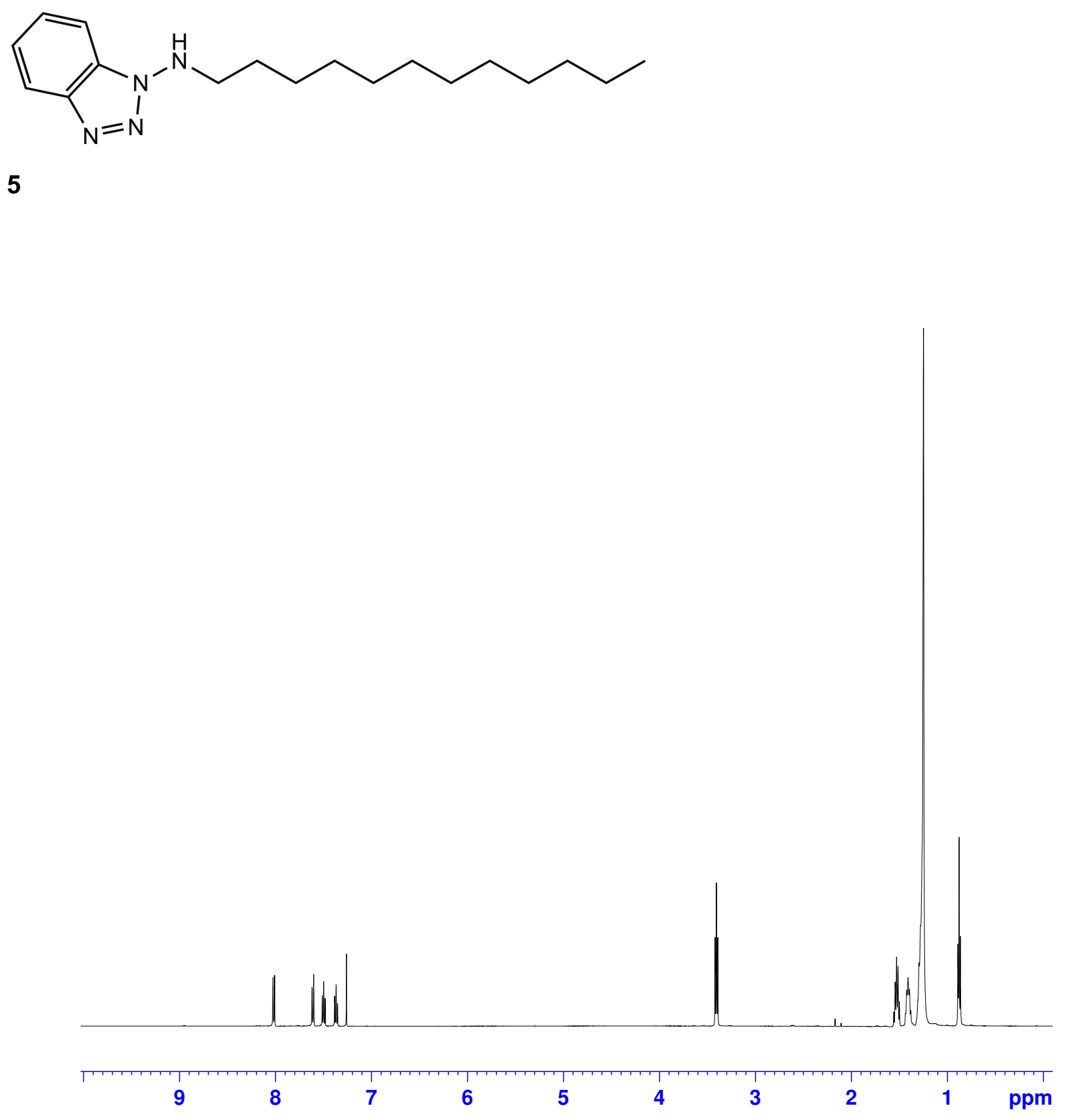
${ }^{13} \mathrm{C}$ NMR (125 MHz, $\left.\mathrm{CDCl}_{3}\right)$

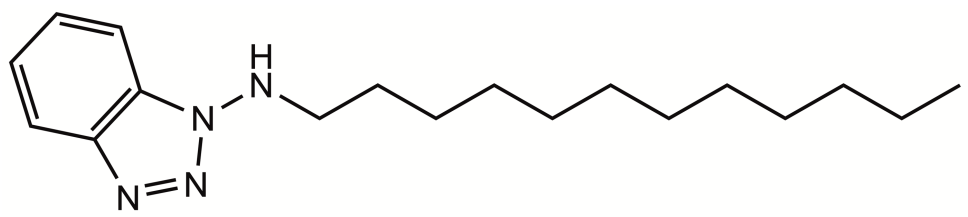

5

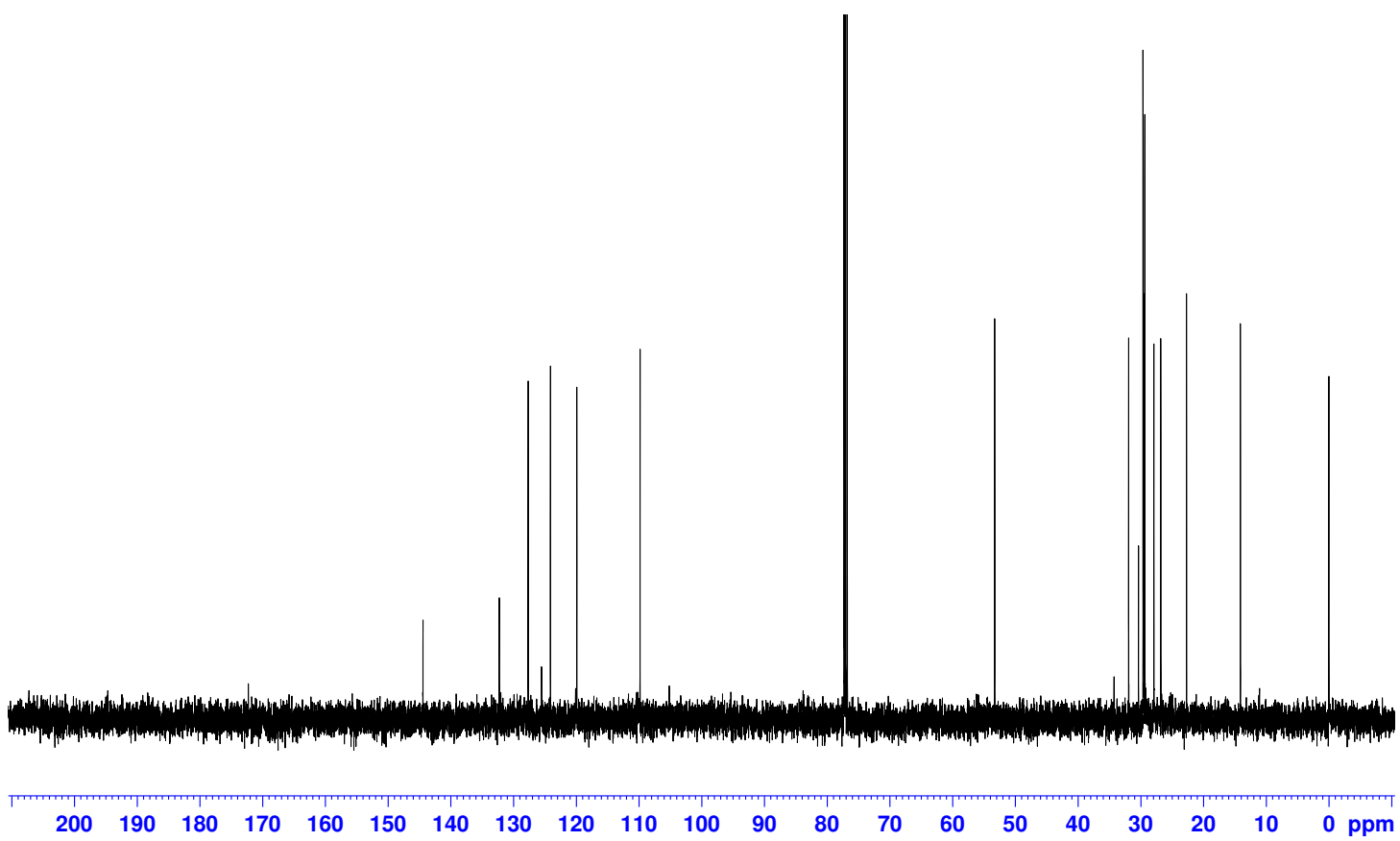


${ }^{1} \mathrm{H}$ NMR $\left(500 \mathrm{MHz}, \mathrm{CDCl}_{3}\right)$<smiles>O=C(O)CCCCCNn1nnc2ccccc21</smiles>

6

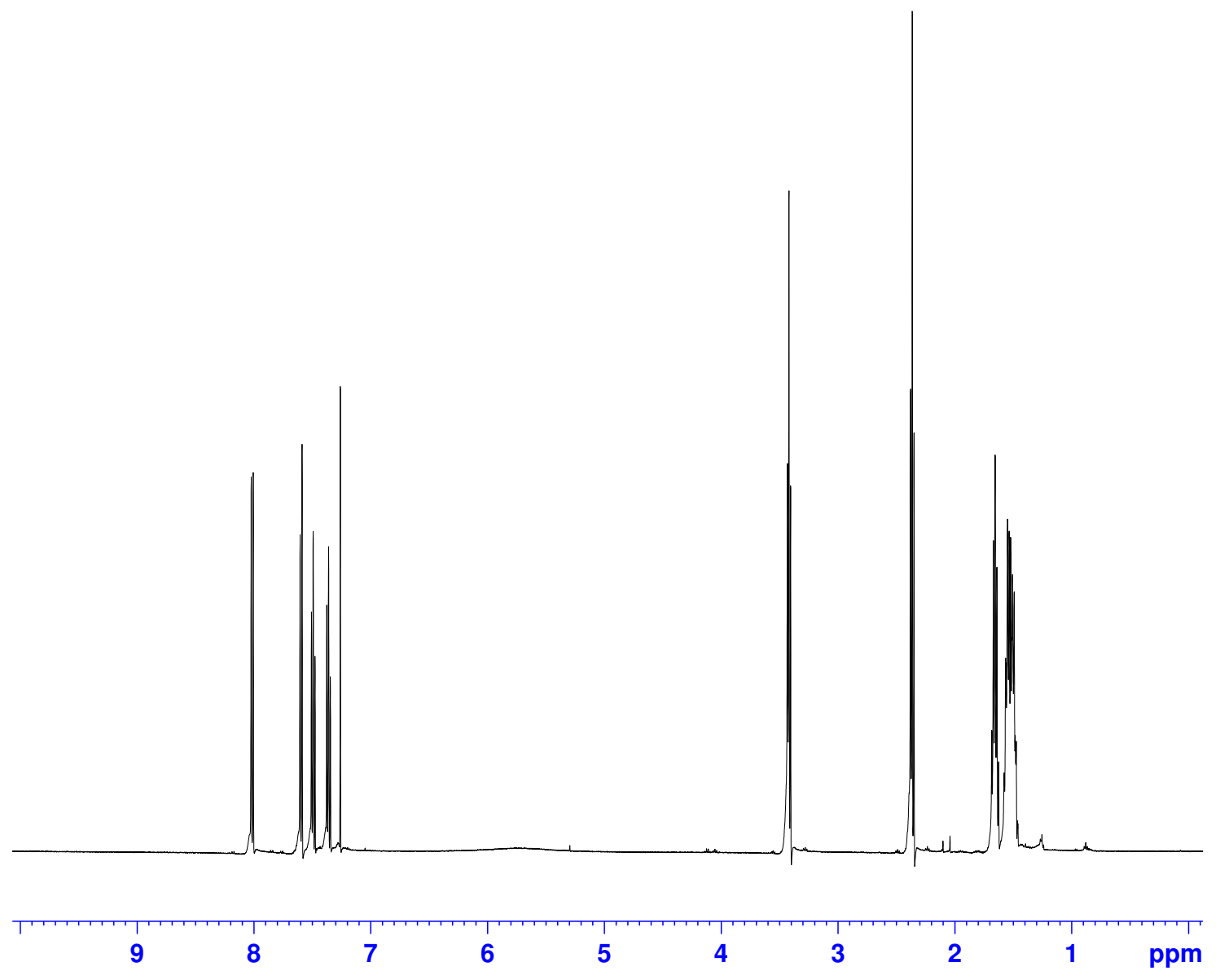


${ }^{13} \mathrm{C}$ NMR (125 MHz, $\left.\mathrm{CDCl}_{3}\right)$<smiles>O=C(O)CCCCCNn1nnc2ccccc21</smiles>

6

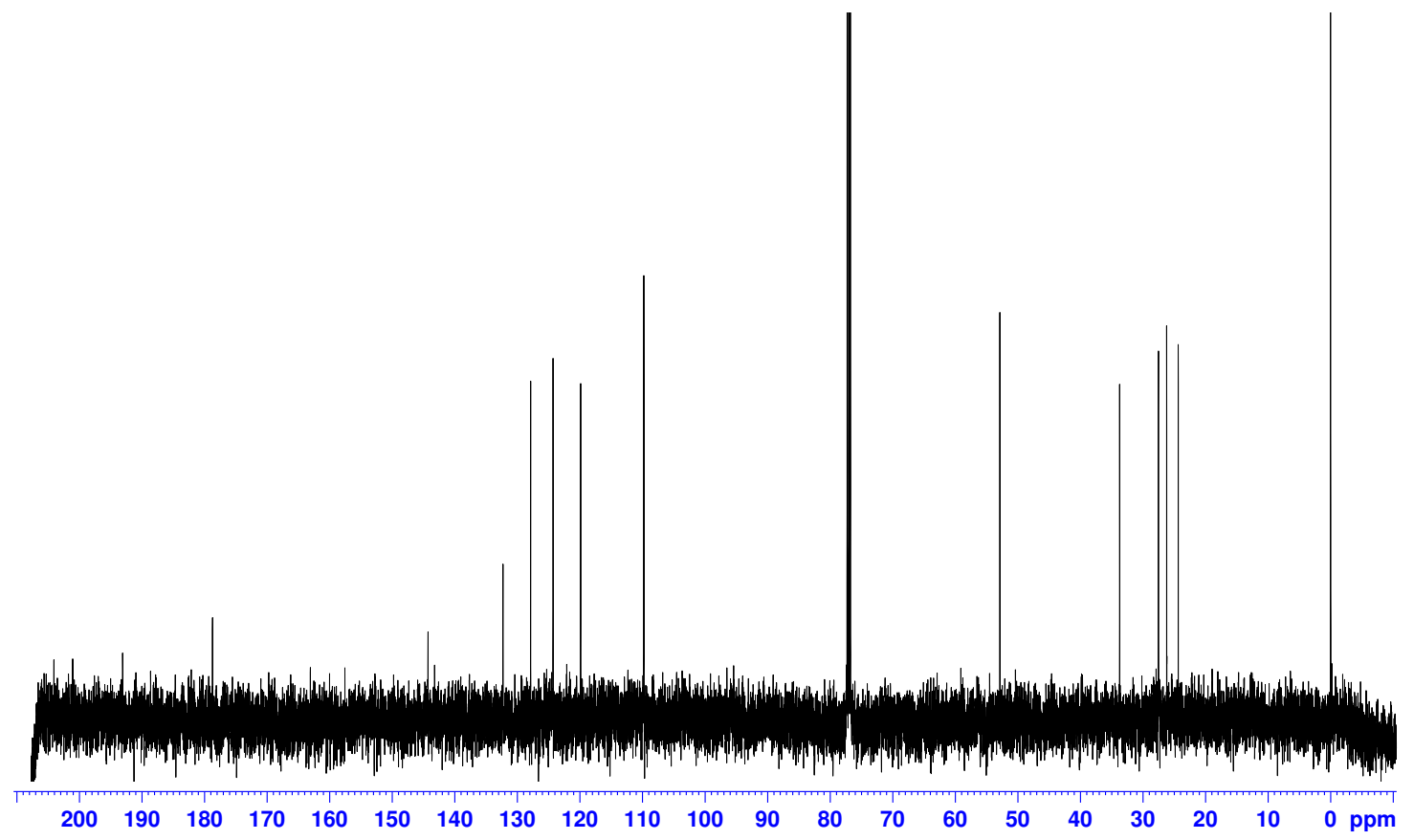


${ }^{1} \mathrm{H}$ NMR $\left(500 \mathrm{MHz}, \mathrm{CDCl}_{3}\right)$<smiles>O=C(O)CCCCCCCNn1nnc2ccccc21</smiles>

7

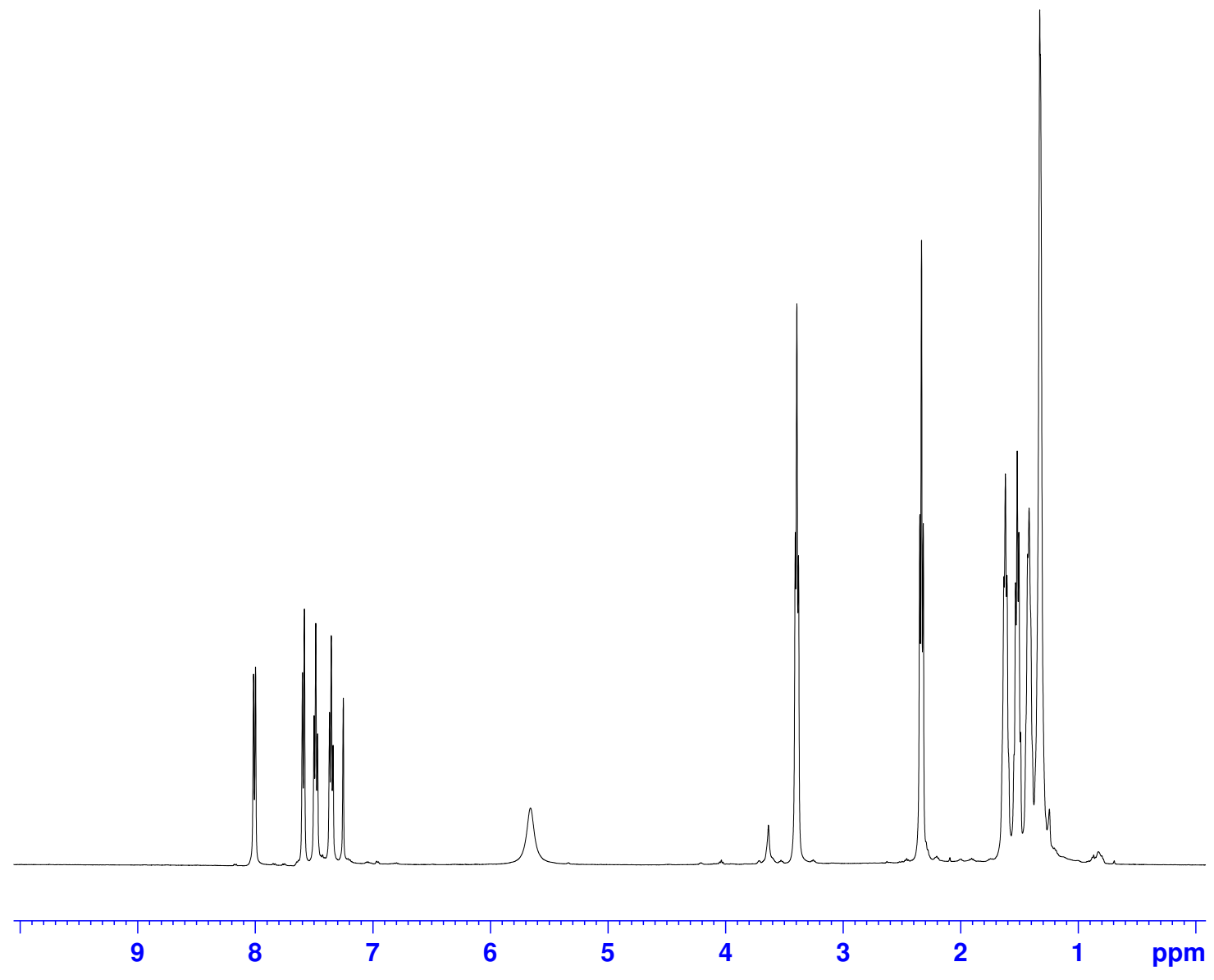


${ }^{13} \mathrm{C}$ NMR (125 MHz, $\left.\mathrm{CDCl}_{3}\right)$<smiles>O=C(O)CCCCCCCNn1nnc2ccccc21</smiles>

7

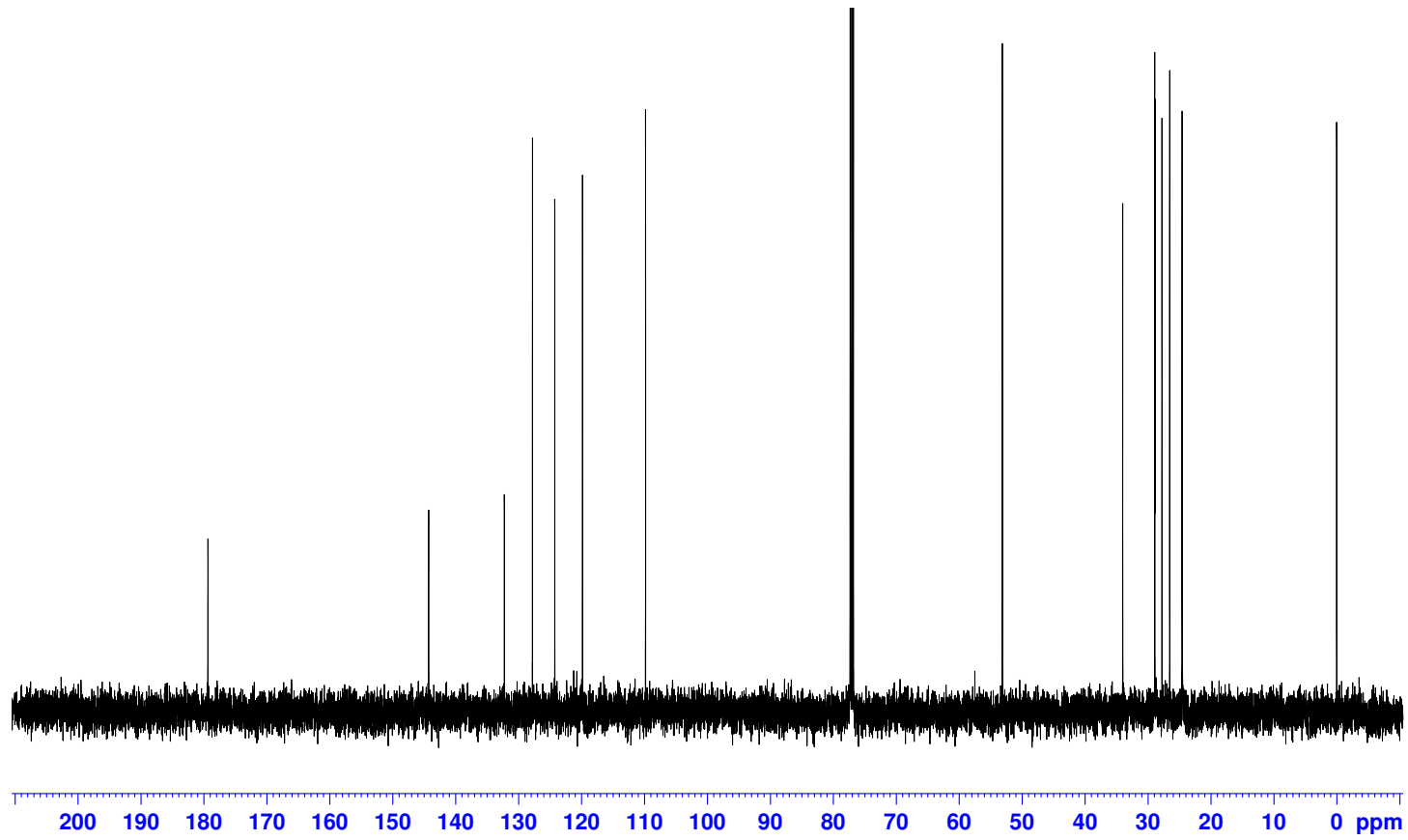


${ }^{1} \mathrm{H}$ NMR $\left(500 \mathrm{MHz}, \mathrm{CDCl}_{3}\right)$<smiles>O=C(O)CCCCCCCCCNn1nnc2ccccc21</smiles>

8

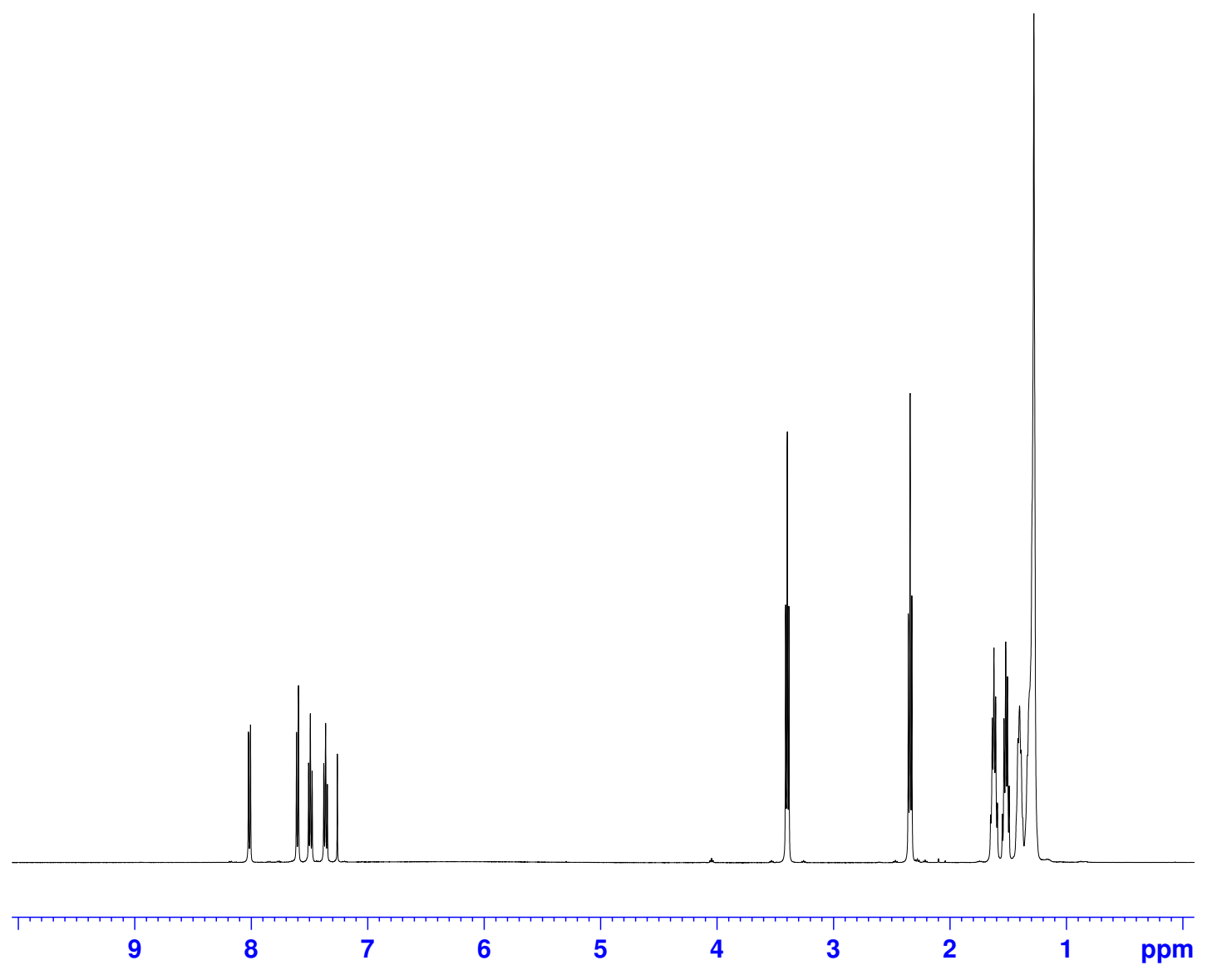


${ }^{13} \mathrm{C}$ NMR (125 MHz, $\left.\mathrm{CDCl}_{3}\right)$<smiles>O=C(O)CCCCCCCCCNn1nnc2ccccc21</smiles>

8

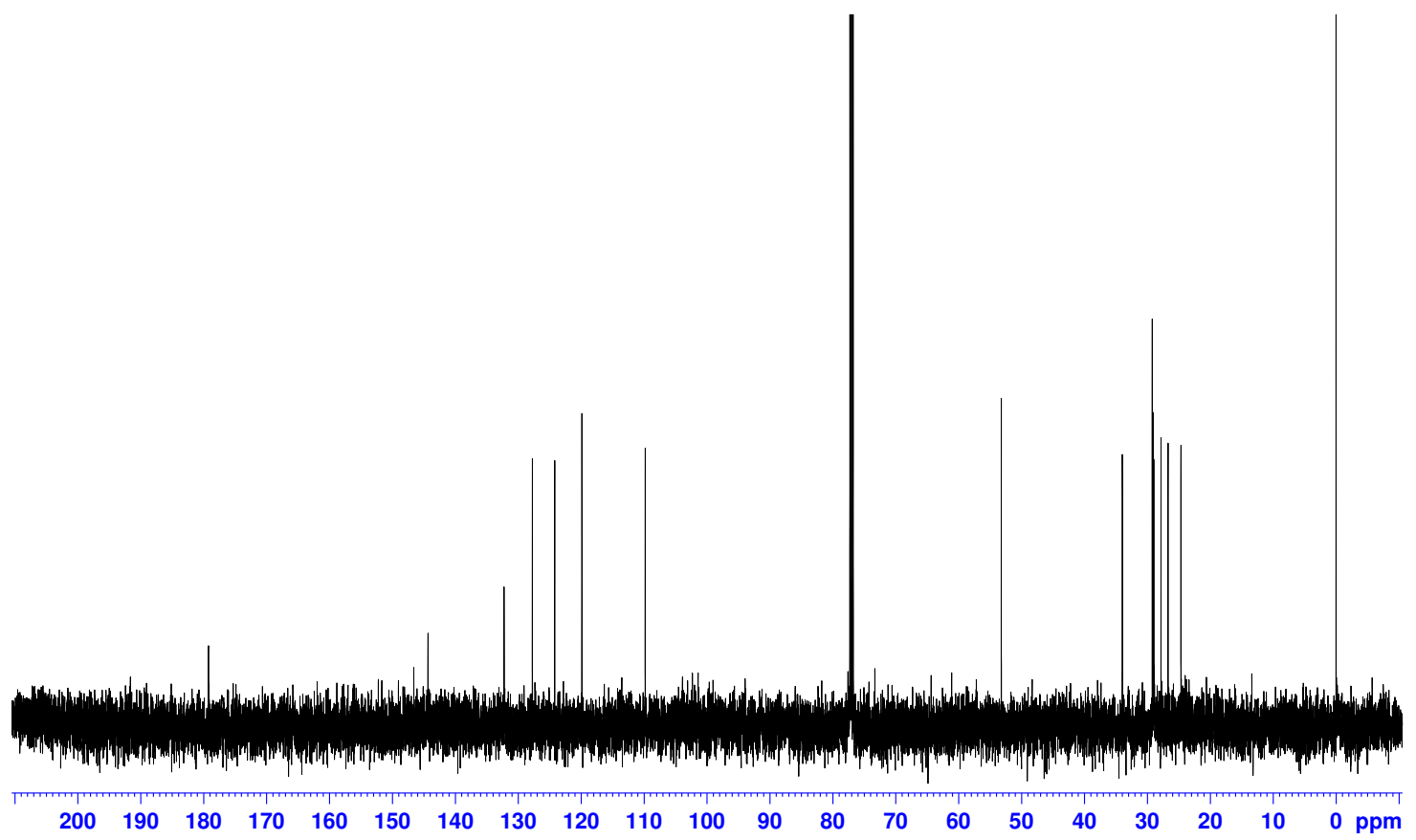


${ }^{1} \mathrm{H}$ NMR $\left(500 \mathrm{MHz}, \mathrm{CDCl}_{3}\right)$<smiles>O=C(O)CCCCCCCCCCCNn1nnc2ccccc21</smiles>

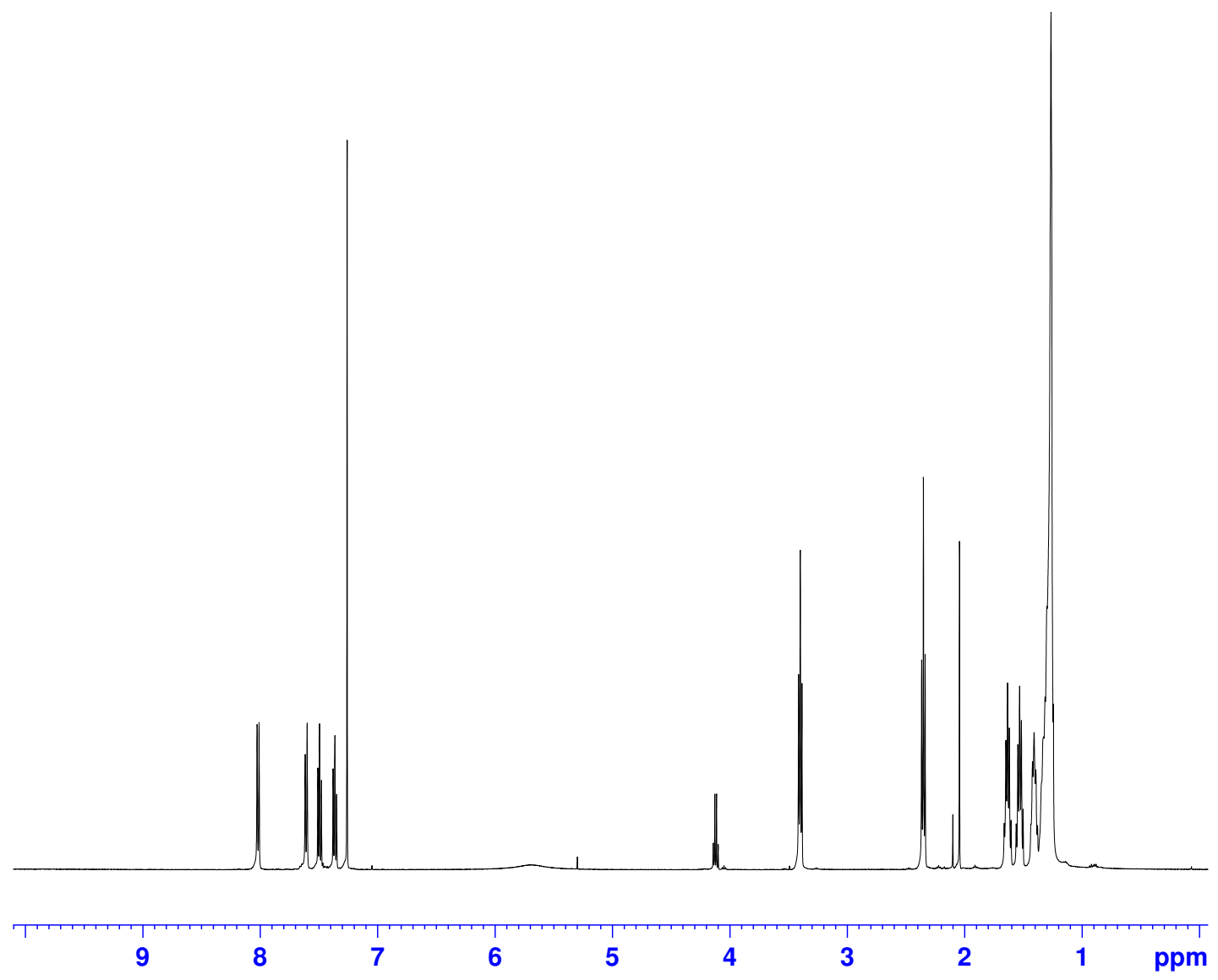


${ }^{13} \mathrm{C}$ NMR (125 MHz, $\left.\mathrm{CDCl}_{3}\right)$<smiles>O=C(O)CCCCCCCCCCCNn1nnc2ccccc21</smiles>

9

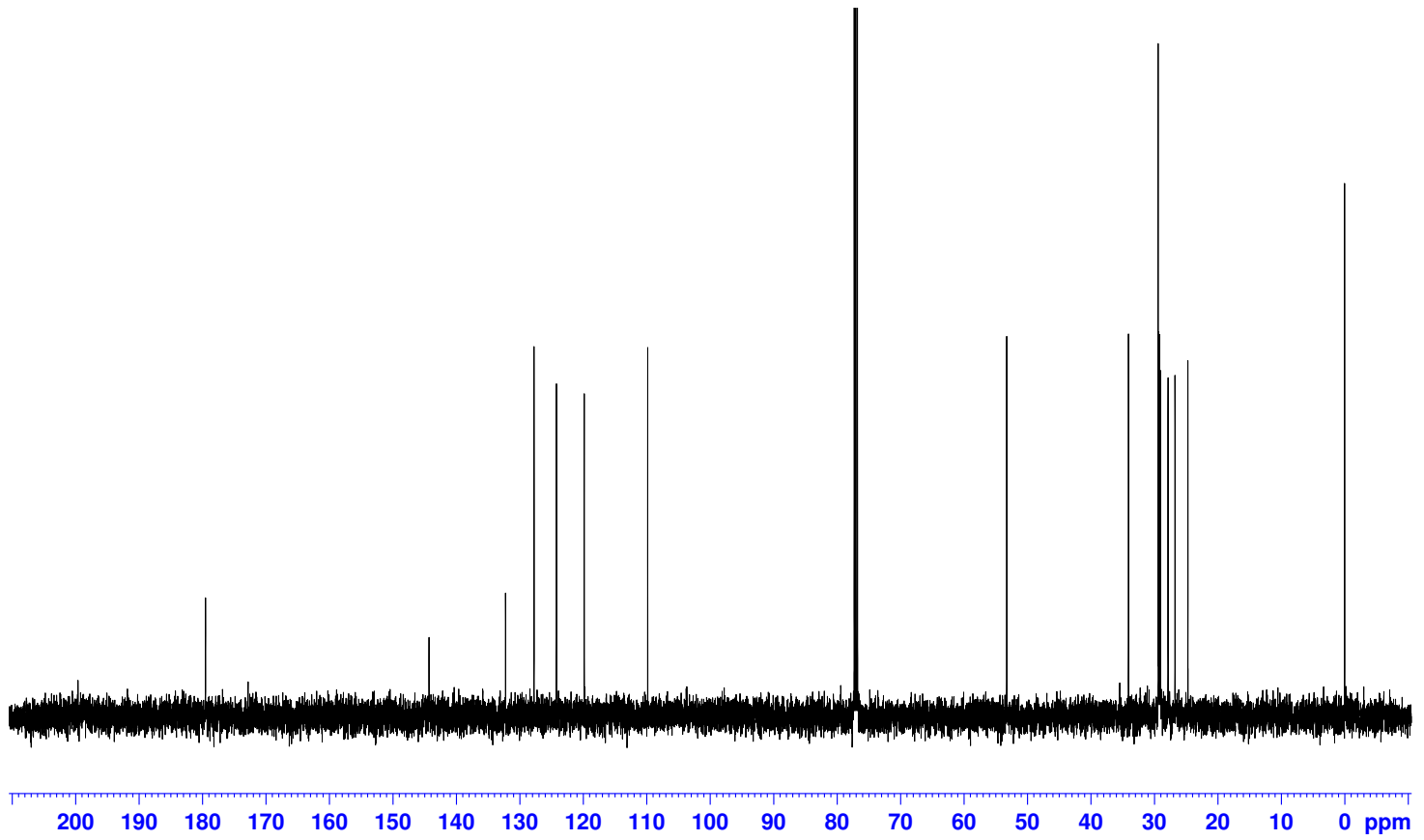

